\title{
Short-term environmental enrichment, and not physical exercise, alleviate cognitive decline and anxiety from middle age onwards without affecting hippocampal gene expression
}

\author{
Gaurav Singhal $^{1}$ (D) Julie Morgan ${ }^{1} \cdot$ Magdalene C. Jawahar $^{1} \cdot$ Frances Corrigan $^{2} \cdot$ Emily J. Jaehne $^{1,3}$. \\ Catherine Toben $^{1}$ • James Breen ${ }^{4,5}$ • Stephen M. Pederson ${ }^{5}$ • Anthony J. Hannan ${ }^{6}$ • Bernhard T. Baune ${ }^{6,7,8}$
}

Published online: 28 August 2019

(C) The Psychonomic Society, Inc. 2019

\begin{abstract}
Physical exercise (PE) and environmental enrichment (EE) have consistently been shown to modulate behavior and neurobiological mechanisms. The current literature lacks evidence to confirm the relationship between PE and EE, if any, and whether short-term treatment with PE, EE, or PE+EE could be considered to correct age-related behavioral deficits. Three-, 8-, and 13month-old C57BL/6 mice were assigned to either PE, EE, or PE+EE treatment groups ( $\mathrm{n}=12-16 /$ group) for 4 weeks before behavioral testing and were compared to controls. Differential effects of the treatments on various behaviors and hippocampal gene expression were measured using an established behavioral battery and high-throughput qPCR respectively. Short-term EE enhanced locomotor activity at 9 and 14 months of age, whereas the combination of PE and EE reduced locomotor activity in the home cage at 14 months. Short-term EE also was found to reverse the age-related increase in anxiety at 9 months and spatial memory deficits at 14 months of age. Conversely, short-term PE induced spatial learning impairment and depressive-like behavior at four months but showed no effects in 9- and 14-month-old mice. PE and PE+EE, but not EE, modified the expression of several hippocampal genes at 9 months of age compared with control mice. In conclusion, short-term EE may help to alleviate age-related cognitive decline and increase in anxiety, without altering hippocampal gene expression. On the contrary, PE is detrimental at a young age for both affective-like behaviors and spatial learning and memory but showed no effects at middle and late middle age despite hippocampal gene expression alterations.
\end{abstract}

Keywords Environmental enrichment $\cdot$ Exercise $\cdot$ Depression $\cdot$ Anxiety $\cdot$ Cognition $\cdot$ Brain $\cdot$ Behavior $\cdot$ Aging $\cdot$ Gene

Bernhard T. Baune

Bernhard.Baune@ukmuenster.de

1 Psychiatric Neuroscience Lab, Discipline of Psychiatry, University of Adelaide, Adelaide, SA, Australia

2 Division of Health Sciences, University of South Australia, Adelaide, SA, Australia

3 School of Psychology and Public Health, La Trobe University, Bundoora, Melbourne, VIC, Australia

4 Robinson Research Institute, University of Adelaide, Adelaide, SA, Australia

5 Bioinformatics Hub, School of Biological Sciences, University of Adelaide, Adelaide, SA, Australia

6 Florey Institute of Neuroscience and Mental Health, University of Melbourne, Melbourne Brain Centre, Melbourne, VIC, Australia

7 Department of Psychiatry, Melbourne Medical School, University of Melbourne, Melbourne, VIC, Australia

8 University Hospital Department of Psychiatry and Psychotherapy, University of Münster, Albert-Schweitzer Campus 1, Building A 9, 48149 Münster, Germany

\section{Introduction}

In the past, there have been numerous studies vastly covering the effects of physical exercise (PE) and environmental enrichment (EE) on affective and cognitive behaviors, locomotion and spatial learning, and memory at various age points, but a comparative study over the life span has never been undertaken. PE, which broadly includes forced running on a treadmill or voluntary running on wheels in cages for rodents, has been shown to improve locomotion (Gentile et al., 1987), enhance spatial memory acquisition, retention, and retrieval (Van Praag et al., 2005; Chen et al., 2006; Van der Borght et al., 2007; Ahmadiasl et al., 2003; Albeck et al., 2006; Alomari et al., 2013; Anderson et al., 2000), augment cognitive abilities (Radák et al., 2001; Nichol et al., 2009; Griesbach et al., 2009; Ma et al., 2017), and alleviate anxiety- and depressive-like behaviors (Binder et al., 2004; Duman et al., 2008; Salam et al., 2009; Helmich et al., 2010; Huang et al., 2017). Physical exercise also has been shown to 
alter molecular biology, such as monoamine metabolism (Ahmadiasl et al., 2003; Samorajski et al., 1987) and neurotrophin levels in the hippocampus (Alomari et al., 2013; Griesbach et al., 2009; Fang et al., 2013; Ferris et al., 2007; Gómez-Pinilla et al., 2002). Evidence suggests that improvement in hippocampal plasticity and neurogenesis is a prerequisite for change in brain functions in response to PE (Van Praag et al., 2005; Chen et al., 2006; Nichol et al., 2009; Ma et al., 2017).

In rodents, the external environment can be enriched with a variety of toys and novel objects, and this has been shown to elicit a considerable influence on neuronal plasticity and brain functions during aging (Singhal et al., 2014). Such rodents exhibited higher locomotion (Gentile et al., 1987; Van de Weerd et al., 1994), improved visuospatial attention performances and recognition memory (Falkenberg et al., 1992; Harati et al., 2011), enhanced cognition (Kobayashi et al., 2002), and decreased anxiety- and depressive-like behaviors (Richter et al., 2013; Brenes et al., 2008) in preclinical trials. Also, EE has been shown to enhance neurogenesis and neuronal survival (Birch et al., 2013), increase synaptic plasticity and synaptogenesis (Birch et al., 2013; Nakamura et al., 1999), and improve neurotrophin (Falkenberg et al., 1992; Birch et al., 2013), monoamine (Brenes et al., 2008; Rasmuson et al., 1998), and glucocorticoid (Olsson et al., 1995) metabolism in the hippocampus of rodents.

Many studies in rodents investigated the effects of either $\mathrm{PE}$ or EE, and not their combination, on behavior, memory, neurobiology, and underlying molecular biology (Gentile et al., 1987; Van Praag et al., 2005; Radák et al., 2001; Samorajski et al., 1987; Van de Weerd et al., 1994; Falkenberg et al., 1992; Rasmuson et al., 1998; Hoffmann et al., 1987; Bowling et al., 1993). Most studies on EE in recent time, however, also have utilized running wheels as a tool of enrichment (Duffy et al., 2001; Morley-Fletcher et al., 2003; Leggio et al., 2005; Segovia et al., 2006; Cui et al., 2006; Yang et al., 2006; Benaroya-Milshtein et al., 2004; Novkovic et al., 2015). The rationale behind the inclusion of running wheels in the EE paradigms is still unclear, and this may have been a source of bias in such behavioral studies on EE. Nevertheless, like PE and EE, the combination of PE and $\mathrm{EE}$ (PE+EE) has been shown to improve cognition, spatial learning and memory (Kobayashi et al., 2002; Leggio et al., 2005; Segovia et al., 2006; Frick et al., 2003; Frick \& Fernandez, 2003; Hüttenrauch et al., 2016), and alleviate anxiety- and depressive-like behaviors (Cui et al., 2006; Yang et al., 2006; Benaroya-Milshtein et al., 2004; Hüttenrauch et al., 2016; Sampedro-Piquero et al., 2013). Neurobiological and molecular changes in the brain, for example, enhanced hippocampal neurogenesis (Segovia et al., 2006) and dendritic growth (Leggio et al., 2005), improved neurotransmission (Segovia et al., 2006) and HPA axis reactivity (Morley-Fletcher et al., 2003; Laviola et al., 2004), and increased BDNF levels in the brain (Novkovic et al., 2015) also have been reported after PE+EE.

The abovementioned functional change in the brain after $\mathrm{PE}, \mathrm{EE}$, and PE+EE may involve change in gene expression, particularly in the hippocampus, because the effects of EE and $\mathrm{PE}$ on the brain results primarily from a change in hippocampal integrity (Van der Borght et al., 2009; Pham et al., 1999; Gobbo \& O'Mara, 2004). Indeed, it has been reported that external environment influences gene expression and genegene interactions, thereby suggesting that modulation of the external environment could be used as a tool to modify gene expression in the brain (Izzotti, 2009). Independent studies have shown that after PE, EE, and PE+EE, genes associated with immune functions, aminergic pathways, neurotrophin metabolism, HPA axis activity, transcription factors, and mitochondrial function express differentially in the brain, thereby improving neural functions and biology (Falkenberg et al., 1992; Rasmuson et al., 1998; Olsson et al., 1995; Hüttenrauch et al., 2016; Keyvani et al., 2004; Mlynarik et al., 2004; Hullinger et al., n.d.; Buschler \& Manahan-Vaughan, 2017; Torasdotter et al., 1998; Dahlqvist et al., 1999; Zajac et al., 2010; Tong et al., 2001; Rampon et al., 2000; Kaliman et al., 2011). Any change in gene expression, therefore, can alter underlying neurobiology and may manifest into observable behavioral changes. Indeed, enhanced hippocampal neurogenesis and improved affective-like behaviors after EE have been shown to be the outcomes of an increase in the expression of $\mathrm{Ngf}$ and Bdnf (Falkenberg et al., 1992; Torasdotter et al., 1998), and 5-htla receptor (Rasmuson et al., 1998) mRNA in the hippocampus of rats. Similarly, PE has been shown to regulate the Sirt1 and Tnf activity, thereby playing a key role in cellular energy metabolism, gene transcription, immune response, and, consequently, in cell survival (Kaliman et al., 2011). The differential effects of PE, EE, and $\mathrm{PE}+\mathrm{EE}$ on hippocampal gene expression across life-span, however, remain unexplored.

The changes in behavior, memory, neurobiology, cellular and molecular functions, and hippocampal gene expression after PE, EE, and PE+EE may differ. Perhaps, the age and sex of an animal also influence behavioral and neurobiological response after $\mathrm{PE}, \mathrm{EE}$, and $\mathrm{PE}+\mathrm{EE}$ as has been reported previously (Harati et al., 2011; Frick et al., 2003; Frick \& Fernandez, 2003; Kim et al., 2004; Lin et al., 2011). It also seems probable that when $\mathrm{PE}$ and $\mathrm{EE}$ are combined, this could potentiate the individual effects of both treatments. These research questions remain unanswered in the absence of a direct comparison between the three treatments. This study, therefore, examined the differential effects of short-term PE, EE, and the combination of PE and EE on the locomotor activity, affective-like behaviors, and spatial and retention memory at three time-points over the lifespan of healthy male and female C57BL/6 mice. The change in the expression of 43 genes of interest in the hippocampus, which were selected after 
extensive literature review and included 12 immune (e.g., Illb, Tnf, Aifl, Gfap), 9 monoamine (e.g., Htrlaa, Grin2a, Tph2), 4 growth factors (e.g., Bdnf, Ngf, Igf1), 5 transcription factor (e.g., Creb1, Smad2, Foxo3), 3 HPA axis (Nr3cl, Crhr1, Crh), and 10 mitochondrial (e.g. Sirt1, Gpx1, Prkaal) function-related genes also has been investigated in response to the abovementioned treatments. We tested the hypothesis that short-term PE and EE of 4 weeks will reverse the aging-associated impairment in brain functions, and hippocampal genes expression in early (4 months), middle (9 months), and late-middle age (14 months) male and female C57BL/6 mice compared with age-matched control mice and that the combination of short-term PE and EE will have additive beneficial effects than PE and EE alone. Together, this allowed us to investigate the potential underlying mechanisms whereby these three treatments can enhance neuronal function and ensure healthy aging.

\section{Methods}

\section{Animals}

Wild-type $(\mathrm{C} 57 \mathrm{BL} / 6)$ mice $(\mathrm{n}=158 ; 80$ males and $78 \mathrm{fe}$ males), parental substrain Nhsd (derived from a colony from the National Institutes of Health), were bred in-house and housed in same-sex groups of four to five in individually ventilated cages (IVCs) in the Laboratory Animal Services facility at the University of Adelaide. In time-period of the experiments, the $\mathrm{C} 57 \mathrm{BL} / 6 \mathrm{Nhsd}$ line has inbred between 913 generations. The strain of the mice is important as it has been reported that $\mathrm{C} 57 \mathrm{BL} / 6$ mice are more reactive and alert to the external environmental stimuli (Van de Weerd et al., 1994). All mice were given ad libitum access to standard laboratory food and water and were maintained under controlled conditions of temperature $\left(21 \pm 1{ }^{\circ} \mathrm{C}\right)$, humidity $(55$ $\%)$ and a 12:12-hour dark-light cycle. This study was approved by the University of Adelaide Animal Ethics Committee (M-216-12), and all guidelines as prescribed for handling the experimental animals were followed during the study.

\section{Experimental design}

Once of the desired age ( 3,8 , and 13 months), mice that showed no signs of injury and sickness were distributed equally into three treatment (Physical exercise (PE), Environmental Enrichment (EE), and $\mathrm{PE}+\mathrm{EE}$ ) and control groups (Figure 1). Mice were randomly paired (males and females paired separately) and transferred to open top cages on the morning of Monday, week 1 ( 2 mice per cage unless fighting necessitated separation). Control mice received no intervention and were kept in cages with the following dimensions: $48.5 \mathrm{~cm} \mathrm{x}$
Age at which mice were housed in IVC cages and treatments (Control, EE, PE, PE+EE) started
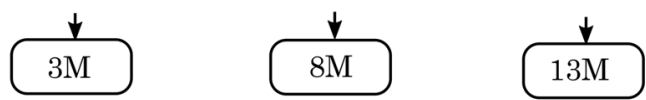

Age at the end of 4 weeks of treatment when behavioral testing commenced

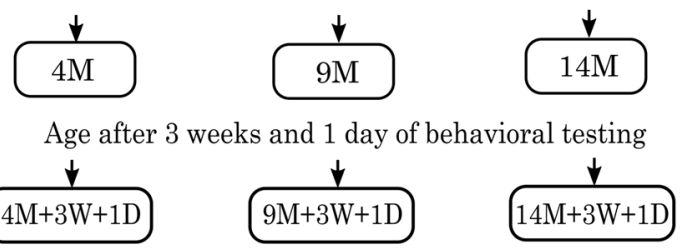

Mice were sacrificed and hippocampal tissues extracted for gene expression analysis the day after behavioral testing ended.

Figure 1. Methodology used during research. Four weeks of treatments are considered equivalent to 1 month of treatments for the sake of simplicity. IVC $=$ individually ventilated cage; $\mathrm{PE}=$ physical exercise; $\mathrm{EE}=$ environmental enrichment; $\mathrm{M}=$ month; $\mathrm{W}=$ week .

$15.5 \mathrm{~cm} \times 12 \mathrm{~cm}$. PE, EE, and PE +EE mice were kept in plexiglass cages with dimensions: $37 \mathrm{~cm}$ x $20.5 \mathrm{~cm} \times 13.5 \mathrm{~cm}$, because these had more breadth and depth to provide extra space for running wheel and the objects associated with EE. Mice were inspected daily but handled only once a week while transferring them to clean cages every Friday morning, starting on the Friday of week 1. Friday was selected for change of cages to allow mice to acclimatize to the fresh bedding for 2 days before the Home Cage test is performed after 4 weeks of treatment. At the same time, mice were weighed on a digital weighing scale. Mice were monitored for dominancy throughout the experiments, and those found to be dominant were segregated to prevent dominance effects on behavior and gene expression. Only the EE mice received nesting material (paper shreds) during the experiments.

The groups assigned as $\mathrm{PE}$ and $\mathrm{PE}+\mathrm{EE}$ were provided with a running wheel for 4 weeks before behavioral testing, i.e., starting when the mice were 3, 8, and 13 months of age. Wheels were made of metal and had the following dimensions: $12 \mathrm{~cm}$ in diameter and $5.5 \mathrm{~cm}$ wide. Running wheels remained in cages throughout the behavioral testing period. Wheel revolutions were counted using an automated counter on the wheels every Friday during change of cages. At the same time, wheels were cleaned using F10SC veterinary disinfectant. Final readings of the wheel revolutions were taken the day after the behavioral testing ended. The total number of revolutions was then multiplied by the circumference of the wheels, i.e., $37.7 \mathrm{~cm}$, to obtain the total distance traveled. Because the mice were kept in pairs, the total distance traveled for one cage reflects the distance traveled by a pair of mice. Distance traveled was then converted into kilometers for statistical analysis.

The groups assigned as EE and $\mathrm{PE}+\mathrm{EE}$ were provided with a variety of nontoxic objects (toys, nonchewable novel plastic, and wooden objects, two types of houses - house on the cage 
floor and house suspended from the open-top roof, colored plastic balls of different texture, hanging toys, ladder, and tunnels) and extra bedding as per previously published protocols (Leggio et al., 2005; Spires et al., 2004; Jankowsky et al., 2005) during the same time period (see Table 1 for the EE protocol that we followed over 8 weeks). The objects and bedding were changed once every week to maintain novelty (during change of cages on Fridays to minimize handling stress to mice). The objects remained in the cages throughout the behavioral testing period.

A priori power analysis of the experimental design using the program $\mathrm{G}^{*}$ Power indicated a $98 \%$ chance of detecting a large effect size and a $62 \%$ chance of detecting a medium effect size (defined by Cohen, 1992, as 0.4 and 0.25 of a population standard deviation between the means respectively
(Cohen, 1992)) between the groups significant at the 5\% level (ANOVA: fixed effects, main effects, and interactions). We observed that the power of our analyses would be 0.8 at the moderate effect size of 0.3 with $n=158$, which we deemed acceptable for research.

The first week consisted of only 5 days, because the EE objects were changed every Friday morning during change of cages.

\section{Behavioral analysis}

After 4 weeks of exposure to PE and/or EE, mice underwent a behavioral test battery following established procedures in the laboratory starting at 4,9 , and 14 months of age (4 weeks of

Table 1. Enrichment protocol over 8 weeks

\begin{tabular}{|c|c|}
\hline Week & Objects used for EE \\
\hline 1 (Monday to Friday) & $\begin{array}{l}\text { - House on the cage floor } \\
\text { - Two toys (one ball + a toy with rough texture) } \\
\text { - Straight tunnel } \\
\text { - A couple of round and irregular stones (made of hard plastic) } \\
\text { - Shredded paper as nesting material }\end{array}$ \\
\hline 2 (Friday to Friday) & $\begin{array}{l}\text { - House on the cage floor } \\
\text { - Three toys (one ball + a hanging toy + novel object) } \\
\text { - U-shaped tunnel } \\
\text { - Increase in the number of irregular stones }(4-5) \\
\text { - Shredded paper as nesting material }\end{array}$ \\
\hline 3 (Friday to Friday) & $\begin{array}{l}\text { - House suspended from the open-top cage roof } \\
\text { - Three toys (a different ball + a different hanging toy + novel object) } \\
\text { - Y-shaped tunnel (one arm closed) } \\
\text { - Ladder } \\
\text { - Shredded paper as nesting material }\end{array}$ \\
\hline 4 (Friday to Friday) & $\begin{array}{l}\text { - House suspended from the open-top cage roof } \\
\text { - Three toys (a different hanging toy }+2 \text { novel objects) } \\
\text { - Y-shaped tunnel (all arms open) } \\
\text { - Slope } \\
\text { - Shredded paper as nesting material }\end{array}$ \\
\hline 5 (Friday to Friday) & $\begin{array}{l}\text { - House on the cage floor } \\
\text { - A straight and a U tunnel } \\
\text { - A different ball + two novel objects } \\
\text { - Shredded paper as nesting material }\end{array}$ \\
\hline 6 (Friday to Friday) & $\begin{array}{l}\text { - House suspended from the open-top cage roof } \\
\text { - U tunnel and a ladder } \\
\text { - A couple of circular and irregular stones } \\
\text { - A different ball + a different hanging toy + novel object } \\
\text { - Shredded paper as nesting material }\end{array}$ \\
\hline 7 (Friday to Friday) & $\begin{array}{l}\text { - House on the cage floor } \\
\text { - Y-shaped tunnel (one arm closed) and a slope } \\
\text { - Few irregular stones } \\
\text { - Three novel objects } \\
\text { - Shredded paper as nesting material }\end{array}$ \\
\hline 8 (Friday to Tuesday) & $\begin{array}{l}\text { - House suspended from the open-top cage roof } \\
\text { - Y-shaped tunnel (one arm closed), slope and a ladder } \\
\text { - A different hanging toy + two novel objects } \\
\text { - Shredded paper as nesting material }\end{array}$ \\
\hline
\end{tabular}

Mice were sacrificed for blood and brain collection on Tuesday morning of week 8 . 
treatments are considered equivalent to 1 month of treatments for the sake of simplicity), as per the below schedule:

Week 1: Home cage (Monday), open field (Tuesday)

Week 2: Elevated zero maze (Monday)

Week 3: Barnes maze (Monday to Friday)

Week 4: Forced swim test (Monday)

The behavioral testing was done in order of the least to most stressful tests. All trials were recorded by a ceilingmounted camera and analyzed using Any-maze software ver. 4.70 from Stoelting, USA. To remove the olfactory traces, F10SC veterinary disinfectant was used to clean the testing area during and between behavioral tests.

\section{Locomotor and Exploratory Behaviour}

1. Home cage activity: The general locomotor activity and exploratory behavior of mice were analyzed in home cages with 2-day-old bedding under basal nonstressful conditions according to previously published protocols (Baune et al., 2008). The total distance covered over 5 minutes was recorded as a measure of locomotor activity. Running wheels were removed during the Home cage test, because wheels occupied significant space in the cage and may have affected the home cage activity results. However, mice assigned as EE and PE+EE were left with two random EE objects to keep the environment enriched during the Home cage test.

2. Open Field: Locomotor activity and exploratory behavior of mice under more anxiety-inducing conditions were measured in the Open Field where mice were individually tested in a brightly lit (approximately 600 lumens) square arena of $40 \mathrm{~cm} \mathrm{x} 40 \mathrm{~cm}$, with clear $35-\mathrm{cm}$ high walls, according to previously published protocols (Baune et al., 2008; Hart et al., 2010). The floor was divided into inner $(26.6 \mathrm{~cm} \mathrm{x} 26.6 \mathrm{~cm})$ and outer $(13.4 \mathrm{~cm} \times 13.4 \mathrm{~cm})$ zones. Total distance traveled in Open Field over 5 minutes was measured as an indication of locomotor activity and exploratory behavior.

\section{Anxiety-like Behaviour}

1. Elevated zero maze: The elevated zero maze is a round maze, $105 \mathrm{~cm}$ in diameter, with a $5-\mathrm{cm}$ wide platform $40 \mathrm{~cm}$ above the floor and divided into four equal quadrants (Braun et al., 2011). Two quadrants have 15-cm high walls (closed), and two are open in alternate order. The EZM was placed in a brightly lit (approximately $600 \mathrm{lu}-$ mens) area during the behavioral testing. The mouse was placed on the open quadrant and allowed to explore for 5 minutes according to published protocols (Shepherd et al.,
1994). The time spent by the mouse in closed and open quadrants and the number of head dips were recorded as a measure of anxiety in mice. Increased time spent in closed as opposed to open quadrants, and lower number of head dips is considered indices of anxiety-like behaviors (Wahlsten, 2010).

2. Open Field: Time spent by mice in the inner and outer zones of the Open Field was recorded as a measure of anxiety-like behavior. Less time spent in the inner zone is an index of anxiety-like behavior (Baune et al., 2008; Hart et al., 2010).

\section{Spatial learning and retention memory}

1. Barnes Maze: Change in spatial learning and retention memory was measured using the Barnes Maze, a circular grey platform $91 \mathrm{~cm}$ in diameter and elevated $90 \mathrm{~cm}$ above the ground, with 20 holes on the perimeter: 1 with a hidden escape box and the rest with false boxes. Because the false boxes are too small to enter and looked the same as the target escape box to the mouse, they removed visual cues that might be observed through an open hole. Barnes Maze procedures were performed according to published protocols (Baune et al., 2008; McAfoose \& Baune, 2009; McLay et al., 1998). Time to find the location of the escape box over 4 days of training was recorded. The mice were placed in the centre of the maze and were allowed to locate the escape box for 3 minutes. Three trials separated by $15 \mathrm{mi}-$ nutes were performed for each mouse on a day. Latency to find the location of the escape box was used to assess the spatial learning and visual memory of the mouse in the new environment (O'leary \& Brown, 2012).

On day 5, the position of escape box was changed from the original training position (in NW quadrant) to the probe trial position (in NE quadrant - at 90 degrees). Time to find the location of the escape box in NW quadrant was recorded to assess the retention of spatial memory of the mouse in the new environment (O'leary \& Brown, 2012).

We also calculated the entry errors, i.e., searches of any holes that did not contain the hidden escape box beneath it following the protocol published by Nithianantharajah et al. (Nithianantharajah et al., 2008). This included nose pokes and head deflections over a hole. Increased number of entry errors were considered indices of spatial learning and memory impairment. 


\section{Depressive-like Behaviour}

1. Forced swim test: Duration of immobility (when mice were floating with no movement of limbs in any direction) over 6 minutes in a 4-L circular cylinder, $20 \mathrm{~cm}$ in diameter and $45-\mathrm{cm}$ high and filled two thirds with water (at 23-24 ${ }^{\circ} \mathrm{C}$ ) was recorded using a ceiling-mounted camera as a measure of despair and depression-like behavior (Wahlsten, 2010; Petit-Demouliere et al., 2005; Porsolt et al., 1977).

\section{Gene expression analysis}

Mice were lethally injected intraperitoneally with pentobarbital $(60 \mathrm{mg} / \mathrm{kg}$ IP) a day after forced swim test. Brains were extracted, dissected and hippocampal tissues were stored in RNAlater (Ambion, Life Technologies) at $-80{ }^{\circ} \mathrm{C}$ until further processing.

Quantification of the levels of mRNA of 43 genes of interest (GOI) across various cytokines, monoamines, neurotrophins, and other genes was performed using TaqMan assays (Life Technologies, ThermoFisher, Australia) in the high-throughput qPCR system BioMarkHD ${ }^{\mathrm{TM}}$ (Fluidigm Inc., USA). Briefly, total RNA was extracted from HC tissues stored in RNALater using PureLink RNA mini extraction kit (Ambion) following the manufacturer's instructions. Total RNA was then subjected to reverse transcription using the SuperScript III first-strand cDNA synthesis system (Invitrogen, Australia) according to the manufacturer's instructions. The samples were then prepared for High-throughput qPCR in BioMark HD ${ }^{\mathrm{TM}}$ (Fluidigm Inc.) using a single 14-cycle pre-amplification consisting of $20 \mathrm{ng}$ of each cDNA sample mixed with pooled TaqMan assays (47 assays, including 4 endogenous reference genes, listed in Table 2) and PreAmp Master Mix (Fluidigm Inc.). Real-time quantitative PCR was performed for each TaqMan assay for each sample in a 96.96 dynamic array nanofluidic chip (Fluidigm Inc.). A total of 47 x 96 (Assays $\mathrm{x}$ Samples in duplicates) PCR reactions were performed. Cycle threshold $(\mathrm{Ct})$ values were generated by Fluidigm real-time PCR analysis software (Fluidigm Inc.).

\section{Statistical Analysis}

In GraphPad Prism version 7.02 (GraphPad Software Inc.), all data outliers were removed using the ROUT method, and normality of data distribution was determined by visual inspection of histograms. Further analyses were performed in SPSS statistics version 25.0 (IBM Corporation). The threeway interactions between age, treatments, and sex for body weight, distance traveled on running wheels, locomotion, anxiety- and depressive-like behaviors, and spatial learning and memory were determined using three-way ANOVAs. Following this, the analyses of simple two-way interaction effects between age and treatments for males and females, simple main effects of the treatments, and simple comparisons between the groups were conducted. If the three-way interaction was significant, then two-way ANCOVA was used to control for sex differences while determining the effects of age and treatment on the dependent variable. If the threeway interaction was nonsignificant, the two-way interaction effect of age and treatment on the dependent variable was determined using a two-way ANOVA. Post-hoc analysis was conducted using Tukey's multiple comparison test. Results were presented as mean \pm standard error (SE). Differences were considered statistically significant when $p<0.05$.

Differentially expressed genes were identified by analysis of Ct data measurements taken from the BioMarkHD arrays in R. Briefly, Input expression values $(\mathrm{Ct})$ of house-keeping genes (B2m, Gapdh, Gusb, and Hprt) were compared across all samples to identify outlier samples. Delta $\mathrm{Ct}$ values were normalized against the geometric mean of all sample expression values. Linear mixed-effects models were then used to compare normalized expression between control and treatment groups and adjusted for multiple comparisons using the R package multcomp (Hothorn et al., 2008). Genes were identified as differentially expressed between control and EE groups when the adjusted $p$ values were $<0.05$ with $\mathrm{Z}$ scores indicating the direction of expression change. GeneMANIA was used to identify the molecular pathways modulated by the differentially expressed genes at a false discovery rate (FDR) $<0.05$ (Warde-Farley et al., 2010). We were not able to analyze the sex differences for gene expression due to the relatively smaller sample size of gene expression data compared with behavioral data. This also limits us from performing the correlation analysis between behavioral and gene expression data.

\section{Results}

\section{Animal body weight}

Body weights of mice at the start and end of experiments were statistically analyzed using a two-way and three-way ANOVA, respectively. Body weights were measured in grams and are presented as a mean \pm standard error unless stated otherwise. No statistically significant interaction between age and sex was observed for body weights at the start of the experiment $\left(\mathrm{F}_{(2,152)}=1.001, p=0.370\right)$. There was, however, a statistically significant main effect of age on starting body weights $\left(\mathrm{F}_{(2,152)}=110.741, p<0.001\right)$. The simple pairwise comparison revealed that the mean body weight of 4-month mice was significantly lower than 9- and 14-month-old mice at the start of experiments $(21.3 \pm 0.3$ vs. 
Table 2. Genes of Interest quantified using high-throughput qPCR

\begin{tabular}{|c|c|c|}
\hline Gene symbol & Gene name & TaqMan Assay ID \\
\hline \multicolumn{3}{|l|}{ Monoamine } \\
\hline Slc6a3 & Solute carrier family 6 (neurotransmitter transporter; dopamine); member 3 & Mm00438388 m1 \\
\hline Slc6a4 & Solute carrier family 6 (neurotransmitter transporter; serotonin); member 4 & Mm00439391_m1 \\
\hline Htrla & 5-hydroxytryptamine (serotonin) receptor $1 \mathrm{~A}$ & Mm00434106_s1 \\
\hline$H t r 1 b$ & 5-hydroxytryptamine (serotonin) receptor 1B & Mm00439377_s1 \\
\hline Htr $2 a$ & 5-hydroxytryptamine (serotonin) receptor $2 \mathrm{~A}$ & Mm00555764_m1 \\
\hline Grin $2 a$ & glutamate receptor; ionotropic; NMDA2A (epsilon 1) & Mm00433802_m1 \\
\hline Grial & Glutamate receptor; ionotropic; AMPA1 (alpha 1) & Mm00433753_m1 \\
\hline Gria2 & Glutamate receptor; ionotropic; AMPA2 (alpha 2) & $\mathrm{Mm} 00442822^{-} \mathrm{m} 1$ \\
\hline Tph2 & Tryptophan hydroxylase 2 & Mm00557715_m1 \\
\hline \multicolumn{3}{|c|}{ Growth factors } \\
\hline$B d n f$ & Brain-derived neurotrophic factor & Mm04230607_s1 \\
\hline Ntrk1 & Neurotrophic tyrosine kinase; receptor; type 1 & Mm01219406_m1 \\
\hline$N g f$ & Nerve growth factor & Mm00443039_m1 \\
\hline $\lg f 1$ & Insulin-like growth factor 1 & Mm00439560_m1 \\
\hline \multicolumn{3}{|c|}{ Transcription factors } \\
\hline Crebl & cAMP responsive element binding protein 1 & Mm00501607_m1 \\
\hline Foxp3 & Forkhead box P3 & Mm00475162_m1 \\
\hline Smad2 & SMAD family member 2 & Mm00487530_m1 \\
\hline Smad3 & SMAD family member 3 & Mm01170760_m1 \\
\hline Foxo3 & Forkhead box O3 & $\mathrm{Mm} 01185722 \_\mathrm{m} 1$ \\
\hline \multicolumn{3}{|c|}{ Immune factors and receptors } \\
\hline Illr1 & Interleukin-1 receptor; type I & Mm00434237_m1 \\
\hline$I l 1 b$ & Interleukin-1 beta & Mm00434228_m1 \\
\hline Il6 & Interleukin-6 & Mm00446190_m1 \\
\hline Illo & Interleukin-10 & Mm01288386_ml \\
\hline Ill2a & Interleukin-12a & Mm00434169_m1 \\
\hline $\operatorname{Tnf}$ & Tumor necrosis factor & $\mathrm{Mm} 00443258 \_\mathrm{m} 1$ \\
\hline Tnfrsfla & Tumor necrosis factor receptor superfamily; member 1a & Mm00441883_g1 \\
\hline Tnfrsflb & Tumor necrosis factor receptor superfamily; member $1 \mathrm{~b}$ & Mm00441889_m1 \\
\hline Ifng & Interferon-gamma & Mm01168134_m1 \\
\hline Nlrp3 & NLR family; pyrin domain containing 3 & Mm00840904_m1 \\
\hline Aif1 & Allograft inflammatory factor 1 & Mm00479862_g1 \\
\hline Gfap & Glial fibrillary acidic protein & Mm01253033_m1 \\
\hline \multicolumn{3}{|c|}{ HPA axis/stress response } \\
\hline $\mathrm{Nr} 3 \mathrm{cl}$ & Nuclear receptor subfamily 3 ; group C; member 1 & Mm00433832_m1 \\
\hline Crhrl & Corticotropin-releasing hormone receptor 1 & Mm00432670_m1 \\
\hline Crh & Corticotropin-releasing hormone & Mm01293920_s1 \\
\hline \multicolumn{3}{|c|}{ Mitochondrial function/ROS and oxidation } \\
\hline Sirt1 & Silent mating type information regulation 2 homolog 1 & Mm01168521_m1 \\
\hline Cs & Citrate synthase & Mm00466043_m1 \\
\hline Uqcrcl & Ubiquinol-cytochrome c reductase core protein 1 & Mm00445911_m1 \\
\hline Actb & Beta-actin & Mm02619580_g1 \\
\hline Sodl & Superoxide dismutase 1 & Mm01344233_g1 \\
\hline Sod 2 & Superoxide dismutase 2 & Mm01313000_m1 \\
\hline Gpxl & Glutathione peroxidase & Mm00656767_g1 \\
\hline Cat & Catalase & Mm00437992_m1 \\
\hline Prkaal & AMPK-activated protein kinase 1 & Mm01296700_m1 \\
\hline Prkaa2 & AMPK-activated protein kinase 2 & Mm01264789_m1 \\
\hline \multicolumn{3}{|c|}{ Endogenous references } \\
\hline Gapdh & Glyceraldehyde-3-phosphate dehydrogenase & Mm99999915_g1 \\
\hline Hprt & Hypoxanthine-guanine phosphoribosyl transferase & Mm03024075_m1 \\
\hline Gusb & Glucuronidase; beta & Mm01197698_m1 \\
\hline$B 2 m$ & Beta-2-Microglobulin & $\mathrm{Mm} 00437762 \_\mathrm{m} 1$ \\
\hline
\end{tabular}

$26.2 \pm 0.3$ and $26.7 \pm 0.3 ; p<0.001)$. The analysis of body weights taken at the end of experiments using a three-way
ANOVA showed a nonsignificant interaction between age, treatment, and sex $\left(\mathrm{F}_{(6,134)}=1.808, p=0.102\right)$. A two-way 
ANOVA also revealed a nonsignificant interaction between age and treatment $\left(\mathrm{F}_{(6,146)}=0.837, p=0.543\right)$, as well as the main effect of treatment $\left(\mathrm{F}_{(3,146)}=0.904, p=0.441\right)$, but the main effect of age was significant $\left(\mathrm{F}_{(2,146)}=37.438, p<\right.$ $0.001)$. Body weights of four months mice were significantly lower than both 9- and 14-month-old mice in all experimental groups (Table $3 ; p<0.001$ ).

\section{Distance traveled on wheels during the experimental period}

Three-way ANOVA found a statistically significant three-way interaction between age, treatment, and sex for distance traveled on running wheels $\left(\mathrm{F}_{(2,62)}=3.96, p=0.024\right)$. However, the simple two-way interactions between age and treatment for both males and females were nonsignificant $\left(\mathrm{F}_{(2,62)}=\right.$ $\left.1.666, p=0.197, \mathrm{~F}_{(2,62)}=2.832, p=0.067\right)$. Hence, a twoway ANOVA was conducted to analyze the two-way interaction effect of age and treatment on distance traveled on running wheels, but the result was still nonsignificant $\left(\mathrm{F}_{(2,68)}=\right.$ $0.459, p=0.634$; Fig. 2).

\section{Behavior}

\section{Locomotor activity}

\section{- Home Cage: Distance traveled}

Baseline locomotor activity was measured in the homecage following 1-month exposure to either control conditions, $\mathrm{PE}, \mathrm{EE}$, or PE+EE at 4, 9, and 14 months of age. Distance traveled was measured in meters and is presented as mean \pm standard error, unless stated otherwise. Three-way ANOVA found a significant three-way interaction between age, treatment, and sex $\left(\mathrm{F}_{(6,133)}=2.581, p=0.021\right)$. Further analysis revealed a significant simple two-way interaction between age and treatment for both males $\left(\mathrm{F}_{(6,133)}=2.320, p=0.037\right)$ and females $\left(\mathrm{F}_{(6,133)}=4.018, p=0.001\right)$. There was a significant simple main effect of treatment for males at 14 months $\left(\mathrm{F}_{3}\right.$, 133) $=6.901, p<0.001)$ and females at $4\left(\mathrm{~F}_{(3,133)}=5.604, p=\right.$ $0.001), 9\left(\mathrm{~F}_{(3,133)}=4.198, p=0.007\right)$, and $14\left(\mathrm{~F}_{(3,133)}=\right.$ 4.163, $p=0.007)$ months. Hence, simple pairwise comparisons were conducted for males and females with a Bonferroni adjustment applied (Figure 3A). The 14-month male PE+EE mice were significantly more mobile in home cage than 14-month male control mice $(14.5 \pm 1.2$ vs. $8.2 \pm$ $1.2 ; p=0.001)$ and PE mice $(14.5 \pm 1.2$ vs. $8.6 \pm 1.1 ; p=$ 0.002). Conversely, PE and EE treatments, and not PE+EE, significantly improved the baseline locomotion compared to age matched controls in 14-month female mice $(14.5 \pm 1.2$ and $15.7 \pm 1.2$ vs. $9.4 \pm 1.2 ; p=0.013$ and 0.001 respectively). EE also improved the baseline locomotion of female mice significantly at 9 month compared to age matched controls $(18.1 \pm 1.2$ vs. $12.4 \pm 1.2 ; p=0.003)$ and 4-month EE mice $(18.1 \pm 1.2$ vs. and $12.2 \pm 1.2 ; p=0.001)$. Female PE mice at 4 months, however, showed significantly reduced baseline locomtion than 4-month female control, EE, and PE+EE mice (7.7 \pm 1.2 vs. $12.2 \pm 0.9,12.2 \pm 1.2$, and $12.5 \pm 1.2 ; p=0.016$, 0.036 , and 0.021 respectively), as well as 9- and 14-month female PE mice $(7.7 \pm 1.2$ vs. $15.2 \pm 1$ and $14.5 \pm 1.2 ; p<$ 0.001 for both).

Following above analysis, we controlled baseline locomotion for sex differences using two-way ANCOVA and found a significant two-way interaction between age and treatment $(\mathrm{F}$ $(6,144)=3.384, p=0.004$; Figure 3B). An analysis of simple main effects for age and treatment with statistical significance receiving a Bonferroni adjustment and being accepted at the $p$ $<0.0125$ level for age and $p<0.0167$ for treatment was conducted. EE mice were significantly more mobile than control mice at 9 months $(16.0 \pm 0.876$ vs. $11.7 \pm 0.785 ; p=0.003)$ and 14 months $(13.8 \pm 0.876$ vs. $8.8 \pm 0.876 ; p<0.001)$, and $\mathrm{PE}+\mathrm{EE}$ mice showed significantly higher locomotion than controls at 14 months $(14.0 \pm 0.915$ vs. $8.8 \pm .876 ; p<$ 0.001). Also, EE and PE mice at 9 months showed significantly higher locomotion than 4-month treatment-matched cohorts $(16.0 \pm 0.876$ vs. $11.9 \pm 0.876 ; p=0.004$ and $12.7 \pm 0.784$ vs. $9.1 \pm 0.915 ; p=0.009)$.

\section{- Open Field: Distance traveled}

Mice were again tested for locomotor activity in the open field test 1 day after the home cage. Distance traveled was measured in meters and are presented as mean \pm standard error unless stated otherwise. A three-way ANOVA found nonsignificant interaction between age, treatment, and sex for

Table 3. Mouse body weights at the start and end of the experiment

\begin{tabular}{|c|c|c|c|c|c|c|c|c|}
\hline \multirow[t]{2}{*}{ Age } & \multicolumn{4}{|c|}{ Start of the experiment } & \multicolumn{4}{|c|}{ End of the experiment } \\
\hline & $\mathrm{C}$ & $\mathrm{PE}$ & $\mathrm{EE}$ & $\mathrm{PE}+\mathrm{EE}$ & $\mathrm{C}$ & PE & $\mathrm{EE}$ & $\mathrm{PE}+\mathrm{EE}$ \\
\hline 4 & $21.9 \pm 0.57$ & $21.2 \pm 1$ & $21.1 \pm 0.36$ & $20.5 \pm 0.79$ & $23.8 \pm 0.51$ & $22.7 \pm 0.72$ & $22.8 \pm 0.37$ & $22.8 \pm 0.72$ \\
\hline 9 & $27.4 \pm 1$ & $26.2 \pm 0.83$ & $25.8 \pm 1.1$ & $25.4 \pm 0.53$ & $27.7 \pm 0.85$ & $26.1 \pm 0.36$ & $26.5 \pm 1.14$ & $26.1 \pm 0.60$ \\
\hline 14 & $26.5 \pm 0.98$ & $28.3 \pm 1.09$ & $26.7 \pm 0.56$ & $26.5 \pm 0.70$ & $27.3 \pm 1.1$ & $28.9 \pm 0.67$ & $26.8 \pm 0.47$ & $27.3 \pm 0.67$ \\
\hline
\end{tabular}

All data represented as mean $\pm \mathrm{SEM}, \mathrm{n}=11-19$ per group. 


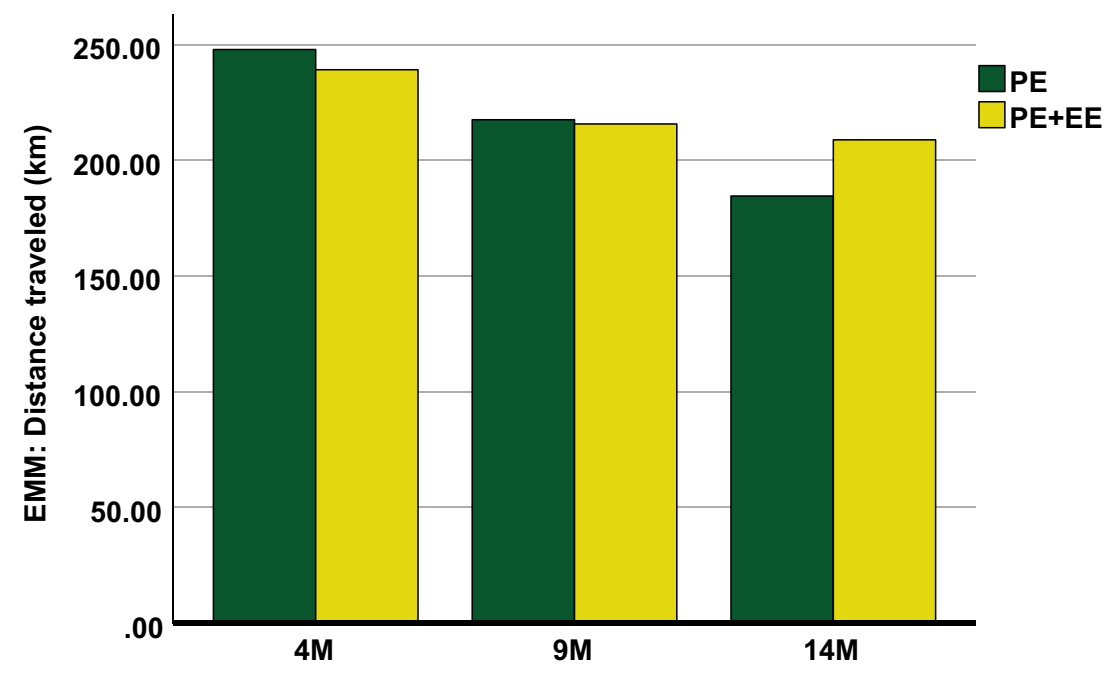

Figure 2. Two-way ANOVA for distance traveled on wheels during the experimental period by separate cohorts of C57BL/6 mice exposed to PE and $\mathrm{PE}+\mathrm{EE}$ conditions. All data represented as estimated marginal means $(\mathrm{EMM}), \mathrm{n}=11-14$ per group.

locomotion in the open field $\left(\mathrm{F}_{(6,132)}=1.694, p=0.127\right)$. The simple two-way interactions between age and treatment were also nonsignificant for both male and female mice $\left(\mathrm{F}_{(6,132)}=\right.$ $1.344, p=0.242$ and $\left.\mathrm{F}_{(6,132)}=1.209, p=0.306\right)$. Hence, no corrections were made for sex differences, and further analysis was performed using a two-way ANOVA. No significant main effects of interaction and age were noted $\left(\mathrm{F}_{(6,144)}=0.782, p=\right.$ 0.586 and $\mathrm{F}_{(2,144)}=0.245, p=0.783$ ); however, the main effect of treatment was found to be significant $\left(\mathrm{F}_{(3,144)}=\right.$ 5.807, $p=0.001$; Figure 4). At 14 months, PE+EE-treated mice traveled significantly less distance than controls $(10.5$ \pm 1.2 vs. $14.7 \pm 0.9 \mathrm{~m} ; p=0.0216$ ). At 9 months, both PE

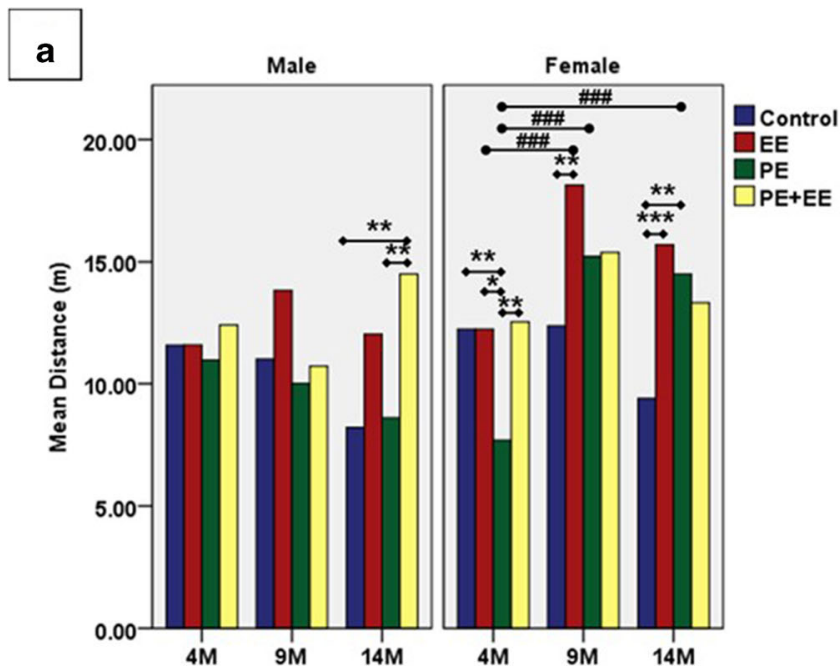

Figure 3. Locomotor activity in Home Cage. (A) Simple pairwise comparisons for distance traveled in the home cage at 4,9 , and 14 months by separate cohorts of male and female C57BL/6 mice exposed to $\mathrm{PE}, \mathrm{EE}, \mathrm{PE}+\mathrm{EE}$ or control conditions. All data represented as mean \pm SE, $n=6-10$ per group. (B) Two-way ANCOVA with sex as a covariate at and PE+EE treated mice showed significantly lower locomotion than EE treated mice $(12.7 \pm 1.1$ vs. $15.8 \pm 0.8 \mathrm{~m} ; p<$ $0.05 ; p=0.0228$ and $10.6 \pm 0.7$ vs. $15.8 \pm 0.8 \mathrm{~m} ; p=0.0002)$.

\section{Anxiety-like behavior}

\section{- EZM: Time in open arms}

Time spent in the open quadrants of EZM is a measure of anxiety-like behavior, with less anxious mice spending more time in the open quadrants. Time was measured in seconds and is presented as a mean \pm standard error unless stated

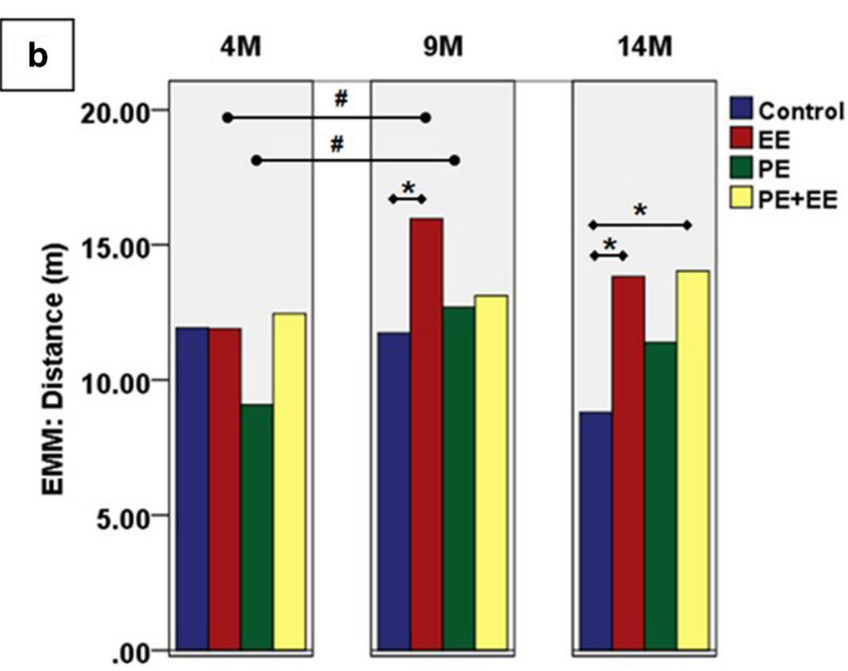

the following value: 1.4904. All data represented as estimated marginal means (EMM), $\mathrm{n}=11-19$ per group. *Significant difference between a treatment and age-matched control or between two treatments at one age point. " Significant difference between the matched treatments over two age points. ${ }^{* \#} p<0.05, * * p<0.01, * * *, \# \#+0.001$. 


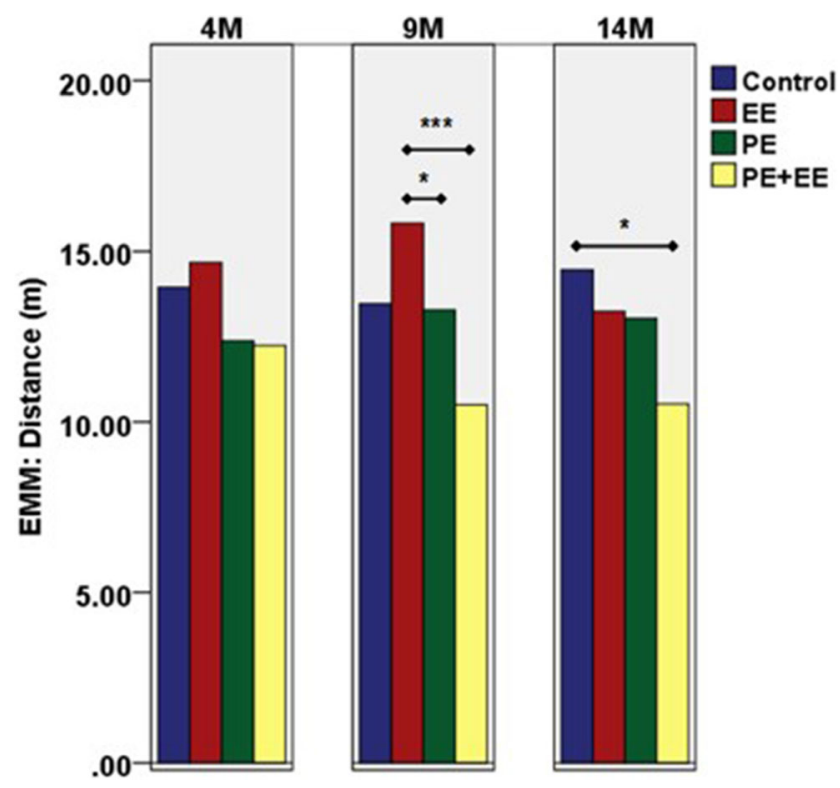

Figure 4. Locomotor activity in Open Field. Two-way ANOVA for distance traveled in the open field at 4, 9, and 14 months by separate cohorts of $\mathrm{C} 57 \mathrm{BL} / 6$ mice exposed to $\mathrm{PE}, \mathrm{EE}, \mathrm{PE}+\mathrm{EE}$ or control conditions. All data represented as estimated marginal means (EMM), $\mathrm{n}=11-19$ per group. *Significant difference between a treatment and age-matched control or between two treatments at one age point. $* p<0.05, * * * p<0.001$.

otherwise. A three-way ANOVA showed statistical significance for the three-way interaction between age, treatment, and sex for time in open arms $\left(\mathrm{F}_{(6,118)}=2.477, p=0.027\right)$. Further analysis showed a statistically significant simple twoway interaction between age and treatment for males $\left(\mathrm{F}_{(6,118)}\right.$ $=3.165, p=0.006)$, but not for females $\left(\mathrm{F}_{(6,118)}=1.599, p=\right.$ $0.153)$. There was a significant simple main effect of treatment for males at 9 months $\left(\mathrm{F}_{(3,118)}=3.680, p=0.014\right)$ and females at 4 months $\left(\mathrm{F}_{(3,118)}=5.211, p=0.002\right)$. Hence, simple pairwise comparisons were run for males and females with a Bonferroni adjustment applied (Figure 5A). Nine-month-old male EE mice were found to spend significantly more time in the open arms of EZM than 4- and 14-month-old male EE mice $(64.3 \pm 8$ vs. $36.8 \pm 8$ and $14.6 \pm 7.3 ; p=0.049$ and $<$ 0.001 respectively), and 9-month-old male PE mice (64.3 \pm 8 vs. $30.7 \pm 6.8 ; p=0.010)$. The time in open arms was significantly low for 14-month male PE+EE mice compared to 4and 9 -month-old male PE+EE mice $(9.3 \pm 7.3$ vs. $42.7 \pm 8$ and $48.3 \pm 8 ; p=0.007$ and 0.001 respectively). For females, 4month-old control mice spent significantly more time in the open arms of EZM than age-matched PE $(52 \pm 6.3$ vs. $9 \pm 8.9$; $p=0.001)$ and 14-month-old control mice ( $52 \pm 6.3$ vs. $23.9 \pm$ $7.3 ; p=0.013$ ).

Using a two-way ANCOVA, we then controlled time in open arms in the EZM for sex differences and found a nonsignificant two-way interaction effect between age and treatment $\left(\mathrm{F}_{(6,129)}=2.152 ; p=0.052\right)$. An analysis of the simple main effects for age and treatment with statistical significance receiving a Bonferroni adjustment and being accepted at the $p$ $<0.0125$ level for age and $p<0.0167$ for treatments showed non-significant main effect of treatment $\left(\mathrm{F}_{(3,129)}=1.736, p=\right.$ $0.163)$ but significant main effect of age $\left(\mathrm{F}_{(2,129)}=16.965, p\right.$ $<0.0001$; Figure 5B). The EE mice at 9 months, and PE+EE mice at 4 and 9 months spent significantly more time in open arms than 14-month EE (56.7 \pm 5.6 vs. $19.7 \pm 5.6 ; p=0.049)$ and PE+EE $(38.0 \pm 5.6$ and $45.2 \pm 5.6 ; p=0.011$ and $<0.001)$ mice respectively. Also, 9-month-old EE mice were found to spend significantly more time in the open arms than 9-monthold PE mice $(56.7 \pm 5.6$ vs. $31.6 \pm 5.1 ; p=0.007)$.

\section{- EZM: Number of Head dips}

The number of head dips along the open quadrants in EZM is a measure of anxiety-like behavior, with less anxious mice showing more number of head dips. Data for head dips is presented as a mean \pm standard error unless stated otherwise. The three-way ANOVA showed a nonsignificant three-way interaction between age, treatment, and sex for head dips in the elevated zero maze $\left(\mathrm{F}_{(6,132)}=1.830, p=0.098\right)$. Two-way interactions between age and treatment for both males and females were also nonsignificant $\left(\mathrm{F}_{(6,132)}=2.083, p=\right.$ 0.059 and $\left.\mathrm{F}_{(6,132)}=.332, \mathrm{p}=0.919\right)$. Hence, no corrections were made for sex differences. Follow-up analysis with a twoway ANOVA showed that the main effect of interaction between age and treatments on the number of head dips in EZM was nonsignificant $\left(\mathrm{F}_{(6,144)}=0.453 ; p=0.842\right)$, but the main effects of treatment and age were significant $\left(\mathrm{F}_{(3,144)}=5.155\right.$; $p=0.002$ and $\mathrm{F}_{(2,144)}=7.367 ; p=0.001$; Figure 6). At 4 months, EE mice showed a significantly higher number of head dips than PE+EE mice $(33.1 \pm 2.6$ vs. $19.8 \pm 1.7 ; p=$ 0.0099). Also, the 4-month controls and EE treated mice showed a significantly higher number of head dips than 14month controls and EE treated mice respectively $(25.2 \pm 1.7$ vs. $15.9 \pm 3.4 ; p=0.0429$ and $33.1 \pm 2.6$ vs. $21.1 \pm 4.4 ; p=$ $0.0143)$.

\section{- Open Field: Time spent in the inner zone}

Time spent in the inner zone of the open field is a measure of anxiety-like behavior, with more anxious mice spending less time in the inner zone. Time was measured in seconds and is presented as mean \pm standard error unless stated otherwise. The three-way ANOVA showed a nonsignificant threeway interaction between age, treatment and sex $\left(\mathrm{F}_{(6,134)}=\right.$ $0.368, p=0.152$ ). Similarly, the two-way interactions between age and treatment for both males and females were also nonsignificant $\left(\mathrm{F}_{(6,134)}=1.195, p=0.313\right.$ and $\mathrm{F}_{(6,134)}=0.202, p$ $=0.976)$. Hence, no corrections were made for sex differences. Following this, a two-way ANOVA was utilized to examine the effects of age and treatments on time spent in the inner zone of open field and found that the main effects of interaction and treatment were not significant $\left(\mathrm{F}_{(6,146)}=\right.$ $1.048 ; p=0.397$ and $\left.\mathrm{F}_{(3,146)}=2.540 ; p=0.059\right)$, but the main 


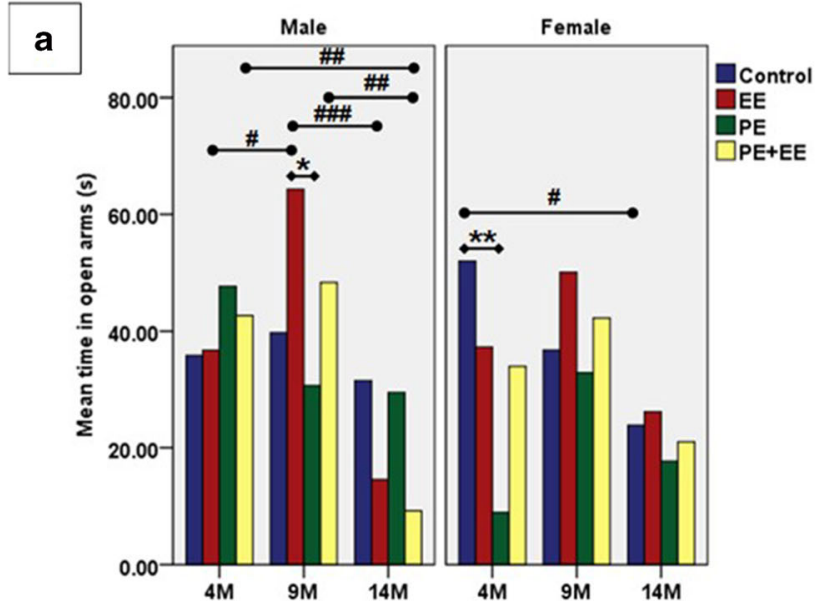

Figure 5. Anxiety-like behavior in EZM. (A) Simple pairwise comparisons for time in open arms in the EZM at 4, 9, and 14 months by separate cohorts of male and female C57BL/6 mice exposed to PE, $\mathrm{EE}, \mathrm{PE}+\mathrm{EE}$ or control conditions. All data represented as mean $\pm \mathrm{SE}, \mathrm{n}=$ 6-10 per group. (B) Two-way ANCOVA for time in open arms in the EZM with sex as a covariate at the following value: 1.4904. All data

effect of age was significant $\left(\mathrm{F}_{(2,146)}=8.805 ; p<0.001\right.$; Figure 7). Post-hoc analysis using Tukey's multiple comparison test showed that 9-month-old control mice spent significantly more time in the inner zone than 4-month control mice $(80.2 \pm 16.2$ vs. $57.9 \pm 8.1 ; p=0.0178)$. Similarly, 9-month PE mice showed significantly higher time in the inner zone than 4- and 14-month PE mice (127.9 \pm 15.9 vs. $75.5 \pm 15.5$ and $76.0 \pm 9.3 ; p=0.0124$ and 0.0124 respectively).

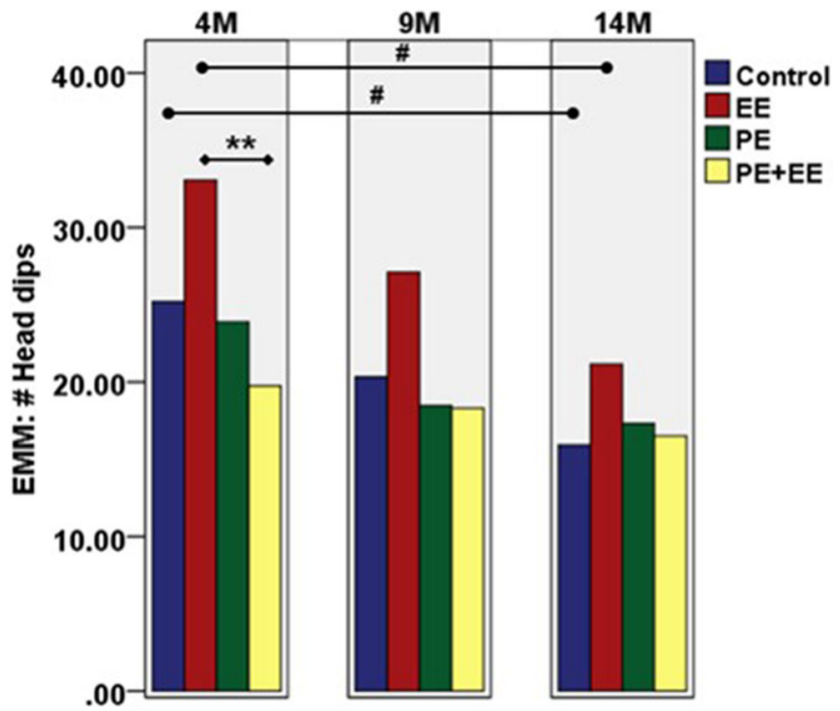

Figure 6. Anxiety-like behavior in EZM. Two-way ANOVA for number of head dips in EZM. All data represented as estimated marginal means $(\mathrm{EMM}), \mathrm{n}=11-19$ per group. $*$ Significant difference between a treatment and age-matched control or between two treatments at one age point. "Significant difference between the matched treatments over two age points. ${ }^{\#} p<0.05, * * p<0.01$.

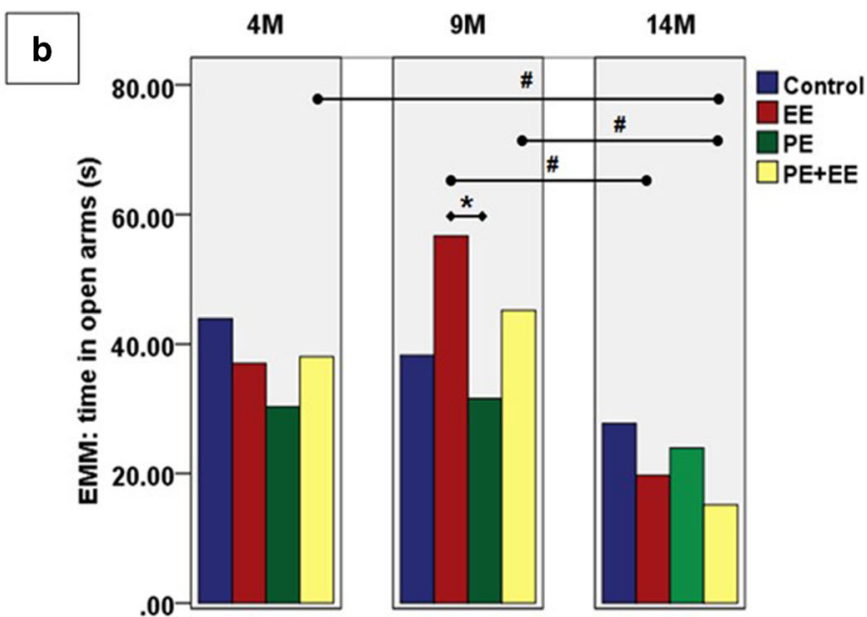

represented as estimated marginal means (EMM), $\mathrm{n}=11-19$ per group. *Significant difference between a treatment and age-matched control or between two treatments at one age point. "Significant difference between

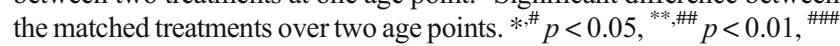
$p<0.001$.

\section{Depressive-like behavior}

\section{- FST: Immobility time}

Mice exposed to PE, EE, PE+EE, or control conditions were tested for depressive-like behavior in the Forced swim test. Time was measured in seconds and is presented as a mean \pm standard error unless stated otherwise. The three-way ANOVA showed a nonsignificant three-way interaction between age, treatment, and sex for immobility time in FST (F

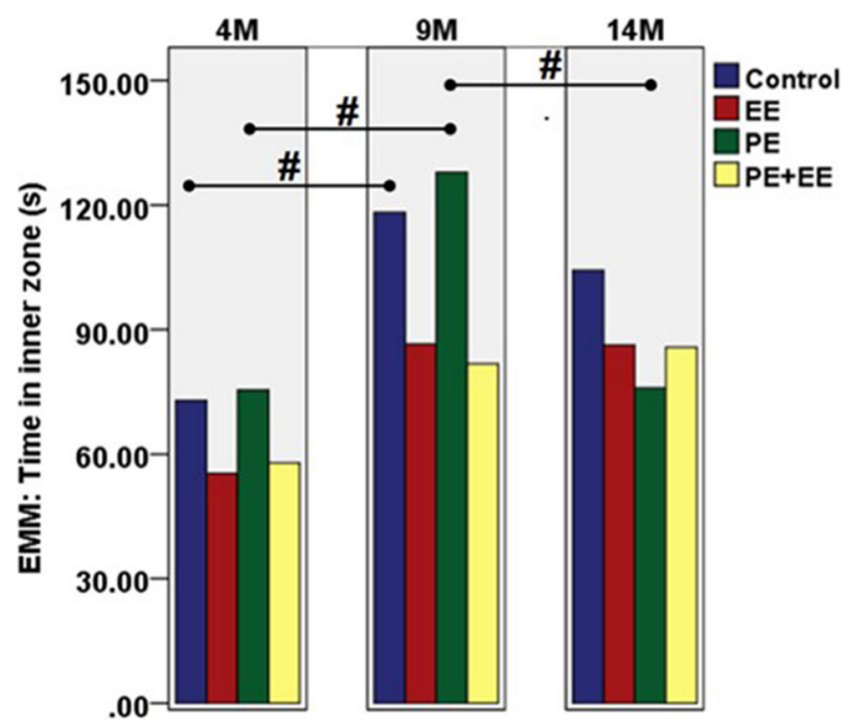

Figure 7. Anxiety-like behavior in Open Field. Two-way ANOVA for time in the inner zone of Open Field. All data represented as estimated marginal means $(\mathrm{EMM}), \mathrm{n}=11-19$ per group. ${ }^{\text {\#Significant difference }}$ between the matched treatments over two age points. ${ }^{\#} p<0.05$. 
$(6,131)=0.627, p=0.708)$. The two-way interactions between age and treatment for immobility time in FST also were nonsignificant for both male and female mice $\left(\mathrm{F}_{(6,131)}=1.005, p\right.$ $=0.425$ and $\left.\mathrm{F}_{(6,131)}=0.658, p=0.684\right)$. As such, no corrections were made for sex. Further analysis with the two-way ANOVA to determine the effects of age and treatments on immobility time in FST showed non-significant main effects of interaction and age $\left(\mathrm{F}_{(6,143)}=1.052, p=0.395\right.$ and $\mathrm{F}_{(2,143)}$ $=0.816, p=0.444)$, but the main effect of treatment was significant $\left(\mathrm{F}_{(3,143)}=5.673 ; p=0.001 ;\right.$ Figure 8$)$. Post-hoc analysis using Tukey's multiple comparison test showed that at 4 months PE mice were immobile for a significantly longer time than both controls and EE treated mice $(82.6 \pm 17.0$ vs. $29.7 \pm 6.9$ and $22.1 \pm 6.9 ; p=0.0171$ and 0.0171$)$.

\section{Spatial learning and memory}

\section{- Spatial learning over 4 days of training in Barnes maze}

Spatial learning at 4, 9, and 14 months in separate cohorts of mice exposed to $\mathrm{PE}, \mathrm{EE}, \mathrm{PE}+\mathrm{EE}$, or control conditions was tested by measuring the latency to find the escape box and entry errors over 4 days of training in Barnes maze. Latency to escape was measured in seconds and is presented as a mean \pm standard error unless stated otherwise. Data was analyzed using three-way ANOVA, which showed a three-way interaction between age, treatment, and sex for spatial learning over 4 days of training $\left(\mathrm{F}_{(6,536)}=2.600, p=0.017\right)$. Post-hoc analysis using Tukey's multiple comparison test showed significant differences between groups at 4 and 14 months for females and 14 months for males (Table 4; Figure 9).

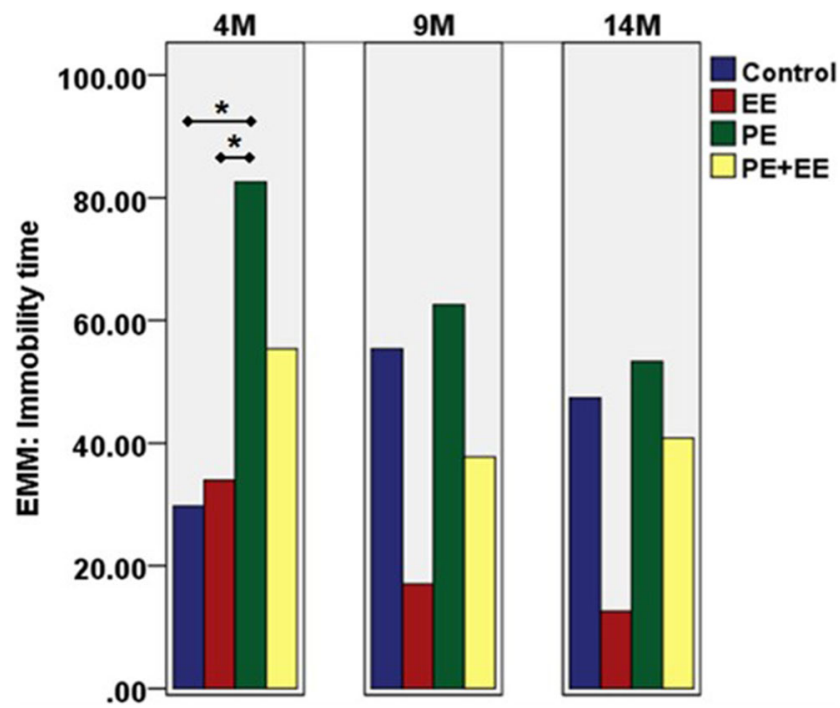

Figure 8. Depressive-like behavior in FST. Two-way ANOVA for immobility time at 4,9 , and 14 months in separate cohorts of animals exposed to PE, EE, PE+EE or control conditions. All data represented mean \pm SEM, $n=12-14$ per group. *Significant difference between a treatment and age-matched control or between two treatments at one age point. $* p<0.05$.
Three-way ANOVA also showed a significant three-way interaction between age, treatment, and sex for entry errors over 4 days of training in Barnes maze $\left(\mathrm{F}_{(6,536)}=4.391, p\right.$ $<0.001)$. However, post-hoc analysis with Tukey's multiple comparison tests showed that none of the male and female groups differed from controls on all 4 days of training, except for female 4-month PE+EE mice, which showed significantly lower entry errors than 4-month female control mice on day 3 $(9.6 \pm 2.8$ vs. $33.4 \pm 8.8 ; p=0.0149)$. Also, 9 - and 14-month male PE mice showed significantly higher entry errors than age-matched male PE+EE (43.7 \pm 4.1 vs. $20.8 \pm 4.7 ; p=$ $0.0334)$ mice on day 1 and EE mice on day 2 (49.0 \pm 9.3 vs. $18.3 \pm 5.5 ; p=0.0013$ ) respectively (Fig 10).

The sex differences for latency to escape and entry errors over 4 days of training in Barnes maze were controlled using a two-way ANCOVA. We observed that the two-way interaction was significant for latency to escape $\left(\mathrm{F}_{(6,583)}=3.191, p=\right.$ $0.004)$ but nonsignificant for entry errors $\left(\mathrm{F}_{(6,583)}=0.504, p\right.$ $=0.805)$. Post-hoc analysis using Tukey's multiple comparisons for latency to escape showed significant differences between groups at 4 and 14 months (Table 5; Figure 11).

Table 5. Multiple comparisons for the effects of EE, PE, and $\mathrm{PE}+\mathrm{EE}$ on latency to escape over 4 days of training in Barnes maze in mice at 4, 9, and 14 months (with sex as a covariate at the following value: 1.4937).

\begin{tabular}{|c|c|c|c|c|}
\hline Months & Day & $\begin{array}{l}\text { Tukey's multiple } \\
\text { comparisons test }\end{array}$ & Mean comparison & $\begin{array}{l}\text { Adjusted } \\
p\end{array}$ \\
\hline \multirow[t]{3}{*}{4} & 1 & Control vs. PE & $\begin{array}{l}46.8 \pm 5.7 \text { vs. } 80.3 \\
\quad \pm 8.2\end{array}$ & 0.0498 \\
\hline & \multirow[t]{2}{*}{3} & Control vs. PE & $\begin{array}{l}28.6 \pm 5.9 \text { vs. } 59.7 \\
\quad \pm 10.4\end{array}$ & 0.0282 \\
\hline & & PE vs. EE & $\begin{array}{l}59.7 \pm 10.4 \text { vs. } 35.7 \\
\quad \pm 8.0\end{array}$ & 0.0368 \\
\hline 9 & \multicolumn{4}{|c|}{$\begin{array}{l}\text { No significant differences between any of the groups were } \\
\text { noted. }\end{array}$} \\
\hline \multirow[t]{10}{*}{14} & \multirow[t]{2}{*}{1} & PE vs. EE & $\begin{array}{l}120.8 \pm 9.7 \text { vs. } 82.3 \\
\quad \pm 11.6\end{array}$ & 0.0255 \\
\hline & & PE vs. $\mathrm{PE}+\mathrm{EE}$ & $\begin{array}{l}120.8 \pm 9.7 \text { vs. } 81.1 \\
\quad \pm 11.2\end{array}$ & 0.0192 \\
\hline & \multirow[t]{2}{*}{2} & PE vs. EE & $\begin{array}{l}81.8 \pm 9.5 \text { vs. } 41.0 \\
\quad \pm 5.4\end{array}$ & 0.0182 \\
\hline & & $\mathrm{PE}$ vs. $\mathrm{PE}+\mathrm{EE}$ & $\begin{array}{l}81.8 \pm 9.5 \text { vs. } 45.8 \\
\quad \pm 7.5\end{array}$ & 0.0369 \\
\hline & \multirow[t]{3}{*}{3} & Control vs. PE & $\begin{array}{l}57.1 \pm 15.3 \text { vs. } 95.0 \\
\quad \pm 16.8\end{array}$ & 0.0234 \\
\hline & & PE vs. EE & $\begin{array}{l}95.0 \pm 16.8 \text { vs. } 37.0 \\
\quad \pm 10.4\end{array}$ & 0.0002 \\
\hline & & $\mathrm{PE}$ vs. $\mathrm{PE}+\mathrm{EE}$ & $\begin{array}{l}95.0 \pm 16.8 \text { vs. } 56.9 \\
\quad \pm 14.0\end{array}$ & 0.0228 \\
\hline & \multirow[t]{3}{*}{4} & Control vs. PE & $\begin{array}{l}50.5 \pm 13.2 \text { vs. } 85.0 \\
\quad \pm 15.9\end{array}$ & 0.0490 \\
\hline & & PE vs. EE & $\begin{array}{l}85.0 \pm 15.9 \text { vs. } 31.4 \\
\quad \pm 8.4\end{array}$ & 0.0006 \\
\hline & & $\mathrm{PE}$ vs. $\mathrm{PE}+\mathrm{EE}$ & $\begin{array}{l}85.0 \pm 15.9 \text { vs. } 46.6 \\
\quad \pm 13.7\end{array}$ & 0.0216 \\
\hline
\end{tabular}

All data represented as mean $\pm \mathrm{SEM}, \mathrm{n}=11-19$ per group. 
Table 4 Multiple comparisons for the effects of EE, PE, and PE+EE on latency to escape over 4 days of training in Barnes maze in male and female mice at 4,9 , and 14 months

\begin{tabular}{|c|c|c|c|c|}
\hline Months & Day & Tukey's multiple comparisons test & Mean comparison & Adjusted $p$ \\
\hline \multirow[t]{8}{*}{4} & 1 & PE females vs. PE+EE females & $84.3 \pm 14.6$ vs. $31.9 \pm 7.5$ & 0.0408 \\
\hline & \multirow[t]{2}{*}{2} & Control females vs. PE females & $29.0 \pm 9.2$ vs. $77.8 \pm 12.0$ & 0.0353 \\
\hline & & PE females vs. EE females & $77.8 \pm 12.0$ vs. $24.8 \pm 9.9$ & 0.0353 \\
\hline & \multirow[t]{3}{*}{3} & Control females vs. PE females & $30.6 \pm 9.7 \pm 81.9 \pm 16.1$ & 0.0154 \\
\hline & & PE females vs. EE females & $81.9 \pm 16.1$ vs. $18.2 \pm 4.0$ & 0.0065 \\
\hline & & PE females vs. PE + EE females & $81.9 \pm 16.1$ vs. $21.7 \pm 9.6$ & 0.0099 \\
\hline & \multirow[t]{2}{*}{4} & Control females vs. PE females & $20.0 \pm 7.1$ vs. $74.0 \pm 17.1$ & 0.0141 \\
\hline & & PE females vs. EE females & $74.0 \pm 17.1$ vs. $22.1 \pm 5.4$ & 0.0372 \\
\hline 9 & \multicolumn{4}{|c|}{ No significant differences between any of the groups were noted. } \\
\hline \multirow[t]{9}{*}{14} & \multirow[t]{5}{*}{3} & PE males vs. EE males & $98.0 \pm 19.7$ vs. $29.1 \pm 9.1$ & 0.0014 \\
\hline & & EE males vs. PE+EE males & $29.1 \pm 9.1$ vs. $81.3 \pm 21.3$ & .0 .0335 \\
\hline & & Control females vs. PE females & $33.9 \pm 9.5$ vs. $91.6 \pm 30.3$ & 0.0151 \\
\hline & & PE females vs. EE females & $91.6 \pm 30.3$ vs. $40.6 \pm 17.8$ & 0.0341 \\
\hline & & PE females vs. PE+EE females & $91.6 \pm 30.3$ vs. $32.4 \pm 12.8$ & 0.0141 \\
\hline & \multirow[t]{4}{*}{4} & PE males vs. EE males & $84.4 \pm 21.8$ vs. $33.3 \pm 7.8$ & 0.0351 \\
\hline & & Control females vs. PE females & $32.8 \pm 15.5$ vs. $85.6 \pm 25.5$ & 0.0325 \\
\hline & & PE females vs. EE females & $85.6 \pm 25.5$ vs. $28.2 \pm 14.1$ & 0.0189 \\
\hline & & PE females vs. PE+EE females & $85.6 \pm 25.5$ vs. $33.7 \pm 8.2$ & 0.0325 \\
\hline
\end{tabular}

All data are represented as mean $\pm \mathrm{SEM}, \mathrm{n}=5-10$ per group.

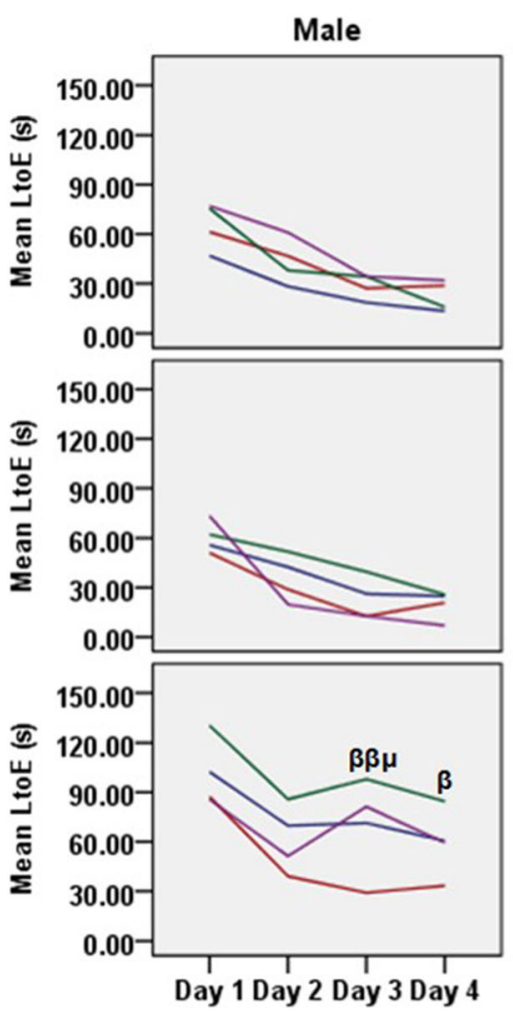

Figure 9. Spatial learning. Latency to find the escape box (LtoE) over 4 days of training at 4 months $(\mathbf{A}), 9$ months $(\mathbf{B})$, and 14 months $(\mathbf{C})$ in separate cohorts of male and female animals exposed to PE, EE, PE+EE,

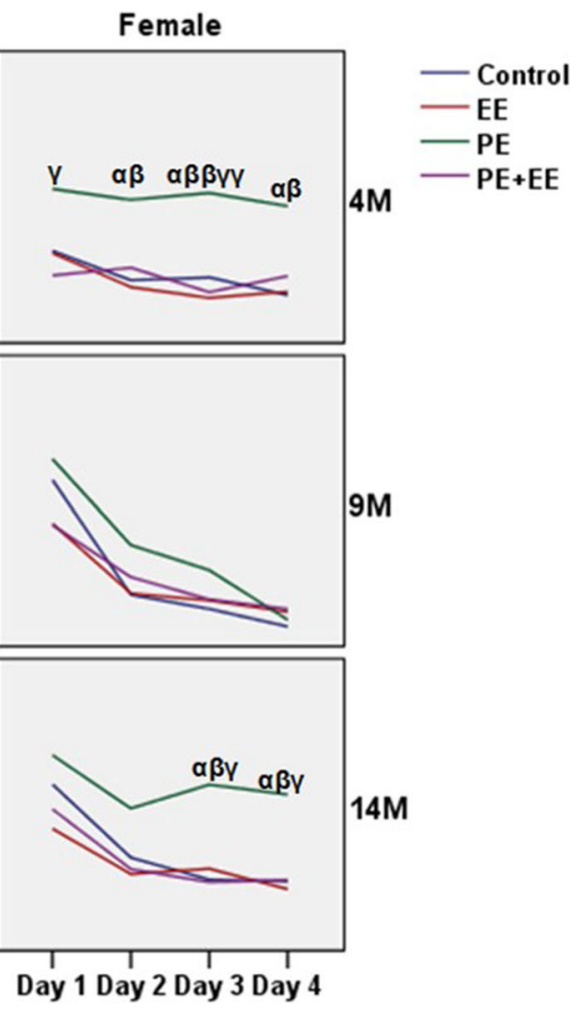

or control conditions in Barnes Maze. All data represented mean $\pm \mathrm{SEM}$, $\mathrm{n}=5-10$ per group. $\alpha$ : Control vs. PE, $\beta$ : PE vs. EE, $\gamma$ : PE vs. PE+EE, $\mu$ : EE vs. PE+EE. $\alpha, \beta, \gamma, \mu: p<0.05, \beta \beta, \gamma \gamma: p<0.01$. 


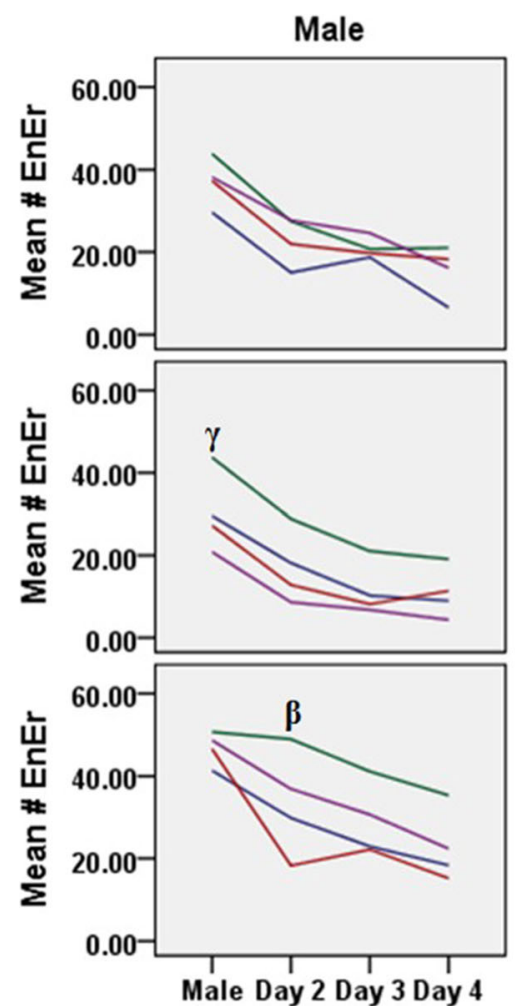

Figure 10. Spatial learning. Entry errors (EnEr) over four days of training at 4 months (A), 9 months (B), and 14 months (C) in separate cohorts of male and female animals exposed to PE, EE, PE+EE, or control

\section{- Retention of spatial learning in Barnes maze probe trial on day 5}

After 4 days of training on Barnes maze, mice were tested for retention of spatial memory in a probe trial on day 5 . Three-way ANOVA showed nonsignificant three-way interaction between age, treatment and sex for both latency to escape $\left(\mathrm{F}_{(6,126)}=0.270, p=0.950\right)$ and entry errors $\left(\mathrm{F}_{(6}\right.$, 134) $=0.739, p=0.619)$. The two-way interactions between age and treatment for latency to escape and entry errors during the probe trial were also non significant for both male $\left(\mathrm{F}_{(6,126)}\right.$ $=0.446, p=0.846$ and $\left.\mathrm{F}_{(6,134)}=1.627, p=0.144\right)$ and female $\left(\mathrm{F}_{(6,126)}=1.431, p=0.208\right.$ and $\left.\mathrm{F}_{(6,134)}=0.935, p=0.472\right)$ mice. Therefore, the data were analyzed again without controlling for sex differences using a two-way ANOVA.

No significant main effects of interaction and treatment were noted for escape latency, but the main effect of age was significant $\left(\mathrm{F}_{(2,139)}=23.11 ; p<0.0001\right.$; Figure 12A). Posthoc analysis showed that at 14-month controls and PE mice had significantly higher latency to find the NW quadrant location of the escape box than EE mice $(110.5 \pm 21.6$ and 107.5 \pm 20.4 vs. $21.0 \pm 8.3 ; p=0.0391$ and 0.0406 ). Similarly, 14 month control, PE and PE+EE mice showed significantly higher latency compared with 4- and 9-month control (110.5 \pm 21.6 vs. $3.7 \pm 0.7$ and $4.1 \pm 1.0 ; p=0.0002$ and $<0.0001)$, 9month PE $(107.5 \pm 20.4$ vs. $6.2 \pm 1.0 ; p<0.0001)$, and 9-

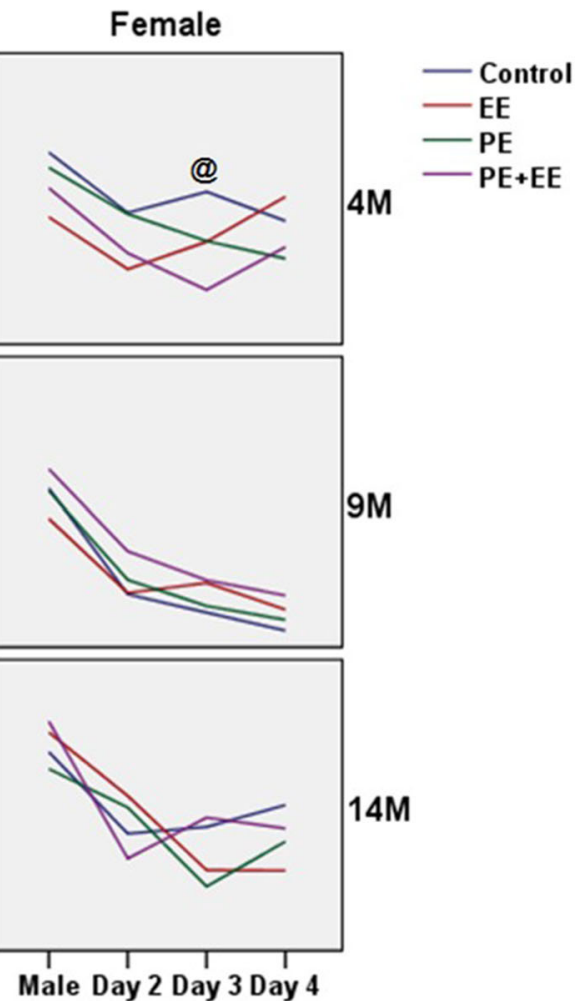

conditions in Barnes Maze. All data represented mean \pm SEM, $n=5-10$ per group. @: Control vs. PE+EE, $\beta$ : PE vs. EE, $\gamma$ : PE vs. PE+EE. $@, \beta, \gamma: p<0.05$.

month PE+EE $(73.4 \pm 21.1$ vs $7.7 \pm 1.4 ; p=0.0140)$ mice, respectively. Also, 4-month PE mice showed significantly higher latency to find the NW quadrant location of the escape box than 9-month PE mice $(68.9 \pm 24.3$ vs. $6.2 \pm 1.0 ; p=$ $0.0163)$.

Using two-way ANOVA, we also noted a significant main effect of age for entry errors $\left(\mathrm{F}_{(2,146)}=8.365 ; p=0.0004\right.$; Figure 12B). Again, this was because of the 14-month-old EE and PE mice showing significantly higher number of entry errors than 4- and 9-month EE $(69.8 \pm 10.6$ vs. $40.8 \pm 11.8$ and $30.7 \pm 7.3 ; p=0.0396$ and 0.0054$)$ and $\mathrm{PE}(63.9 \pm 13.8 \mathrm{vs}$. $26.5 \pm 6.2$ and $29.3 \pm 5.5 ; p=0.0085$ and 0.0085$)$ cohorts.

\section{Changes in the expression of genes of interest in the hippocampus of C57BL/6 mice exposed to short-term $\mathrm{PE}$, EE or $\mathrm{PE}+\mathrm{EE}$}

The differential effects of PE, EE, and PE+EE on hippocampal gene expression were investigated with highthroughput qPCR (43 target genes; Table 2). No effects of any of the treatments on hippocampal gene expression, with an adjusted $p<0.05$ for significance, were observed at 4 and 14 months of age. However, at 9 months, several genes were differentially expressed amongst the groups. Three genes, i.e., Creb1, Smad2, and Illr1 differentially expressed during PE vs. control, PE vs. EE, PE+EE vs. 
Table 5 Differentially expressed genes between control, PE, EE, and PE+EE mice at 9 months of age (listed in order of increasing adjusted $p$ values)

\begin{tabular}{|c|c|c|c|c|c|c|}
\hline Groups compared & Gene & Std. Error & Z & $\mathrm{p}$ values & adjusted $\mathrm{p}$ & $\begin{array}{l}\text { Direction of gene } \\
\text { expression change }\end{array}$ \\
\hline \multicolumn{7}{|l|}{$\mathrm{PE}-\mathrm{C}$} \\
\hline 1 & Crebl & 0.191433 & 4.497535 & $6.87 \mathrm{E}-06$ & 0.0005 & $\uparrow$ \\
\hline 2 & Smad2 & 0.1758727 & 3.857107 & 0.0001 & 0.0042 & $\uparrow$ \\
\hline 3 & Illr1 & 0.4474172 & 3.496435 & 0.0005 & 0.0116 & $\uparrow$ \\
\hline 4 & Sirt1 & 0.1908514 & 3.328333 & 0.0009 & 0.0162 & $\uparrow$ \\
\hline 5 & Ill12a & 0.1965468 & 3.18867 & 0.0014 & 0.0212 & $\uparrow$ \\
\hline 6 & $A c t b$ & 0.1791941 & 3.060445 & 0.0022 & 0.0273 & $\uparrow$ \\
\hline 7 & Prkaa2 & 0.2794528 & 3.006629 & 0.0026 & 0.0279 & $\uparrow$ \\
\hline 8 & Ifng & 0.8951038 & -2.940542 & 0.0033 & 0.0303 & $\downarrow$ \\
\hline 9 & Htrla & 0.500134 & 2.88788 & 0.0039 & 0.0319 & $\uparrow$ \\
\hline 10 & Tnfrsfla & 0.2850217 & -2.829359 & 0.0047 & 0.0330 & $\downarrow$ \\
\hline 11 & Foxo3 & 0.6820933 & 2.813408 & 0.0049 & 0.0330 & $\uparrow$ \\
\hline \multicolumn{7}{|l|}{$\mathrm{PE}+\mathrm{EE}-\mathrm{C}$} \\
\hline 1 & Crebl & 0.1995607 & 6.09142 & $1.12 \mathrm{E}-09$ & 8.28E-08 & $\uparrow$ \\
\hline 2 & Illr1 & 0.4730396 & 4.058302 & 4.94E-05 & 0.0018 & $\uparrow$ \\
\hline 3 & Smad2 & 0.1874809 & 3.235324 & 0.0012 & 0.0225 & $\uparrow$ \\
\hline \multicolumn{7}{|l|}{ PE - EE } \\
\hline 1 & Crebl & 0.1995809 & 4.9507104 & 7.39E-07 & 0.0001 & $\uparrow$ \\
\hline 2 & Smad2 & 0.1836931 & 4.3623256 & $1.29 \mathrm{E}-05$ & 0.0011 & $\uparrow$ \\
\hline 3 & Sirt1 & 0.1993378 & 3.4757951 & 0.0005 & 0.0162 & $\uparrow$ \\
\hline 4 & Prkaa2 & 0.2918789 & 3.3122057 & 0.0009 & 0.0257 & $\uparrow$ \\
\hline 5 & $I l 12 a$ & 0.2052864 & 3.2643984 & 0.0011 & 0.0287 & $\uparrow$ \\
\hline 6 & Illr1 & 0.4669941 & 3.2230505 & 0.0013 & 0.0296 & $\uparrow$ \\
\hline \multicolumn{7}{|l|}{$\mathrm{PE}+\mathrm{EE}-\mathrm{EE}$} \\
\hline 1 & Crebl & 0.2073895 & 6.474284 & $9.53 \mathrm{E}-11$ & 4.23E-08 & $\uparrow$ \\
\hline 2 & Smad2 & 0.1948359 & 3.7443337 & 0.0002 & 0.0081 & $\uparrow$ \\
\hline 3 & Illr1 & 0.4915971 & 3.7846389 & 0.0002 & 0.0081 & $\uparrow$ \\
\hline 4 & $H t r 2 a$ & 0.3305805 & 3.5094451 & 0.0004 & 0.0161 & $\uparrow$ \\
\hline 5 & Prkaa2 & 0.3095843 & 3.1811221 & 0.0015 & 0.0310 & $\uparrow$ \\
\hline 6 & Cs & 0.4501019 & 3.0650659 & 0.0022 & 0.0409 & $\uparrow$ \\
\hline 7 & Prkaal & 0.1962215 & 3.0301516 & 0.0024 & 0.0434 & $\uparrow$ \\
\hline
\end{tabular}

$\mathrm{C}=$ control $\mathrm{PE}=$ physical exercise $\mathrm{EE}=$ environmental enrichment. Data presented were analyzed with a linear mixed-effects model of the treatment groups. Coefficients of the model fit and standard errors are detailed, with test statistics (Z-score) and adjusted $p$ value calculated after correcting for multiple tests.

control, and PE+EE vs. EE comparisons. Similarly, genes Sirt1 and Il12a were found to be differentially expressed on comparing PE with control, and PE with EE groups. The gene Prkaa2 was found to be differentially regulated during PE vs. control, and PE vs. EE group comparisons. Other genes that were differentially expressed during single comparisons only were Actb, Ifng, Htrla, Tnfrsfla, and Foxo3 (PE vs. control), and Htr2a, Cs, and Prkaal (PE+ EE vs. EE). None of the genes differentially expressed during the remaining two comparisons, i.e., EE vs. C and PE vs. PE+EE groups. The differentially expressed genes between the mice groups at 9 months of age are listed in Table 5.

\section{Discussion}

In our study, none of the treatments, i.e., PE, EE, and PE+EE, affected body weight significantly during experiments. Similarly, distance traveled on running wheel during the experiment was not significantly different between the PE and $\mathrm{PE}+\mathrm{EE}$ mice at all three age points, i.e., early (4 months), middle ( 9 months), and late-middle (14 months) age. While short-term EE improved locomotor activity, reversed the agerelated decline in spatial memory and reduced anxiety-like behavior, short-term PE had no effects on spatial memory and affective-like behaviors in middle and late-middle age mice. In early age mice, short-term PE reduced spatial 


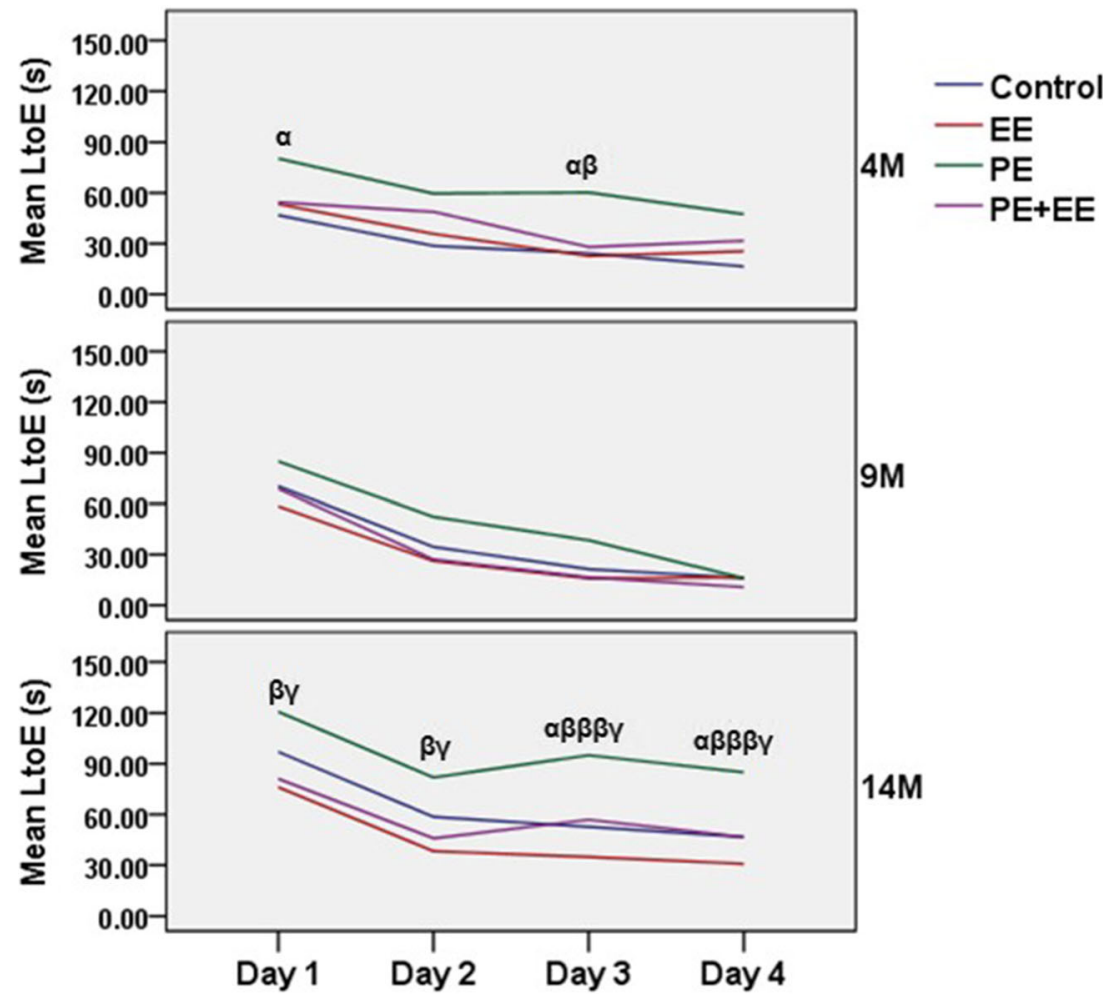

Figure 11. Spatial learning. Latency to find the escape box (LtoE) over 4 days of training in Barnes Maze at 4 months (A), 9 months (B), and 14 months $(\mathbf{C})$ in separate cohorts of animals exposed to PE, EE, PE+EE, or

control conditions with sex as covariate at the following value: 1.4937 . All data represented mean \pm SEM, $\mathrm{n}=11-19$ per group. $\alpha$ : Control vs. PE, $\beta$ : PE vs. EE, $\gamma$ : PE vs. PE+EE. $\alpha, \beta, \gamma: p<0.05, \beta \beta \beta: p<0.001$.

learning and increased depressive-like behavior, particularly affecting female mice. These results on the effects of PE are interesting, knowing that short-term PE alone and in

combination with EE modified the expression of many hippocampal genes of interest in middle-age mice. EE alone showed no effects on the expression of genes of interest in the
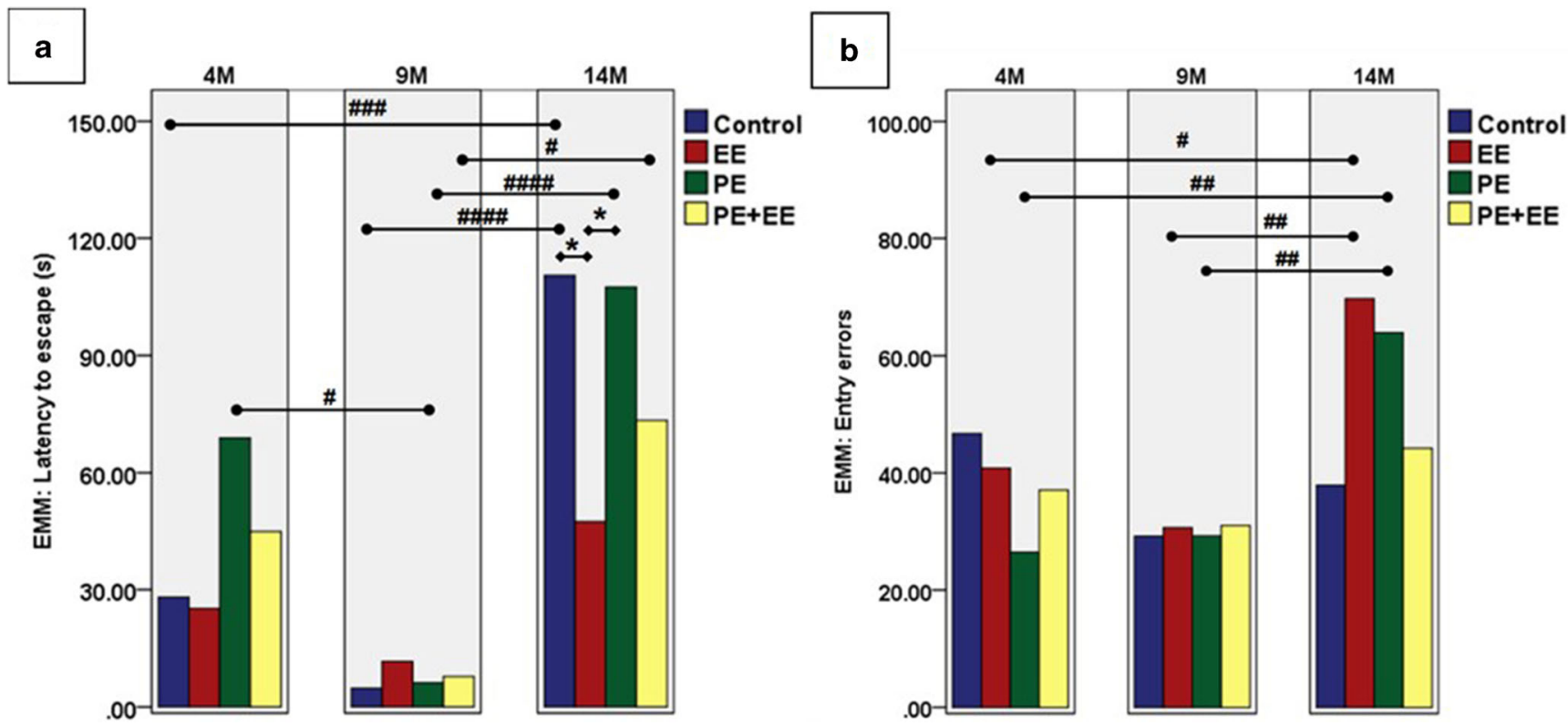

Figure 12. Retention of spatial learning (A) Escape latency to find the escape box and (B) entry errors during probe trial at 4, 9, and 14 months in separate cohorts of $\mathrm{C} 57 \mathrm{BL} / 6$ mice exposed to $\mathrm{PE}, \mathrm{EE}, \mathrm{PE}+\mathrm{EE}$ or control conditions. All data represented as (A) mean \pm SEM, and (B) estimated marginal means (EMM), $\mathrm{n}=11-19$ per group. $*$ Significant

difference between a treatment and age-matched control or two different treatments at one age point. "Significant difference between the matched

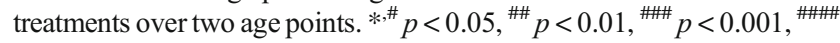
$p<0.0001$. 
hippocampus of mice at all ages. Main findings of our research are discussed below pointwise.

\section{Short-term PE, EE, and combined PE and EE do not affect the mean body weight of C57BL/6 mice.}

Early evidence suggests that PE reduces body weight by mobilizing fats, both within rodents (Crews 3rd et al., 1969; Brown \& Van Huss, 1973; Levin \& Dunn-Meynell, 2004) and humans (Donnelly et al., 2000; Messier et al., 2004). The lack of significant changes in body weight of both male and female mice within our study may be attributable to the short duration of the treatment protocols or the young baseline age of mice with minimal body fat to begin with. Our reasoning is consistent with a previous study that reported a decrease in body weight only in response to continuous exercise and not intermittent exercise (Donnelly et al., 2000). Similarly, EE of 6 weeks that included a running wheel in 10-week-old mice resulted in no change in body weight (Benaroya-Milshtein et al., 2004). We did not investigate the body composition of mice or food intake in the study, and recommend this be investigated in similar future studies to get more clarity on the effects of external interventions on body weight. We also theorize that a lengthier exposure to voluntary $\mathrm{PE}$ on mice older than late-middle age may show observable changes in body weights.

\section{EE improves baseline locomotion from middle age onwards. PE+EE, although beneficial at late-middle age, reduces locomotion under stress}

Short-term EE under non-threatening environmental conditions of the home cage induced increased locomotion at 9 and 14 months of age, whereas PE+EE resulted in increased baseline locomotion at 14 months only. The effects of $\mathrm{EE}$ on baseline locomotion is primarily driven by a significant increase in the baseline locomotion of female mice and not male mice at 9 and 14 months. On the contrary, the effects of PE+ $\mathrm{EE}$ at 14 months were driven by the enhanced baseline locomotion of male mice. Furthermore, 4-month-old female PE mice showed significantly reduced baseline locomotion; however, this seems to be compensated by the baseline locomotion of the 4-month male PE mice, thereby resulting in an overall non-significant difference between 4-month PE and agematched control PE mice.

Under more threatening environmental conditions in the open field, PE+EE mice were less mobile at 14 months of age compared with controls. This may be due to the greater anxiety-inducing environment of the open field compared with the home cage. While not significantly different to agematched controls, EE mice outperformed PE and PE+EE mice in exploring the open field at 9 months of age. We observed no sex differences in open field locomotor activity. Our results for locomotor activity comply with the previously published findings. For example, voluntary wheel running of 6 weeks reduced the locomotor activity of 8-weeks-old spontaneously hypertensive male rats in the Open Field test (Hoffmann et al., 1987). EE without running wheel for 39 days has been shown to enhance locomotion in young male Sprague-Dawley rats in the Open Field test (Bowling et al., 1993). Similarly, EE without running wheel for 11 weeks enhanced play behavior in home conditions in newly weaned male mice (Marashi et al., 2004). Overall, our result suggests that EE primarily enhances the locomotor activity of female $\mathrm{C} 57 \mathrm{BL} / 6$ mice, but the effects of PE+EE on locomotor activity depends on the presence or absence of stressful conditions. These results contrast with the previously reported findings in male rodents; however, this can be attributed to the effect of different rodent species and strain used (Van de Weerd et al., 1994). Further research into differentiating the effects of $\mathrm{PE}, \mathrm{EE}$, and $\mathrm{PE}+\mathrm{EE}$ on locomotion after a longer duration of treatment in C57BL/6 mice is required.

\section{$E E, P E$, and $P E+E E$ did not affect anxiety-like behavior compared to age-matched controls at all ages but had an effect across the lifespan}

While none of the treatments were different to controls at all ages for anxiety-like behavior, we found age effects within treatments. Short-term EE and PE mice appeared to exhibit less anxiety-like behavior at 9 months compared with their 4and 14-month cohorts as evident by significantly more time spent in the open quadrants of EZM and inner zone of Open Field respectively. However, sex influenced anxiety-like behavior. We found that EE mice were different due to the significantly less anxiety-like behavior of 9-month male EE mice compared with 4- and 14-month male EE mice. Similarly, PE was found to be anxiogenic for females compared with agematched controls at 4 months. Indeed, PE, when added to EE at 4 months, increased anxiety, as evident by significantly fewer head dips by 4-month PE+EE mice compared with 4month EE mice in the EZM. Furthermore, the observed significant higher anxiety-like behavior of 14-month PE+EE mice compared with 9-month counterparts, as evident by differences between the treatment matched age cohorts for time in open arms of EZM, was primarily due to higher anxietylike behavior in male PE+EE mice. The 14-month controls and EE mice showed significantly less head dips in the EZM than their cohorts at 4 months, suggesting significantly higher anxiety-like behavior at late-middle age compared to early age cohorts in untreated and EE mice during our experiments. Together, our findings point toward EE being anxiolytic at young and middle age, PE being anxiogenic for females at young age and EE when combined with PE may induce anxiety at late-middle age in male C57BL/6 mice. 
$\mathrm{PE}$ and $\mathrm{EE}$, as well as the combination of $\mathrm{PE}$ and $\mathrm{EE}$, are established anxiolytic interventions (Benaroya-Milshtein et al., 2004; Sampedro-Piquero et al., 2013; Fulk et al., 2004; Petruzzello et al., 1991; Görtz et al., 2008). Indeed, both $\mathrm{PE}$ and EE seem to positively affect the ventral hippocampus, a region involved in anxiety response (Görtz et al., 2008; Pietropaolo et al., 2014). Short-term PE+EE has shown to reduce anxiety-like behavior at a young age in female transgenic models of AD (Görtz et al., 2008; Pietropaolo et al., 2014), male $\mathrm{C} 3 \mathrm{H} / \mathrm{eB}$ mice (Benaroya-Milshtein et al., 2004), as well as in healthy male Wistar rats (Sampedro-Piquero et al., 2013). This contradicts our above-reported findings. Similarly, our results also challenge the previously reported findings on PE. For example, voluntary wheel running of 4 weeks when provided to 12- to 14-week-old single house C57BL/6 mice reduced anxiety-like behavior and impulsiveness (Binder et al., 2004). Similarly, 8 weeks old male C57BL/ 6 mice, which underwent voluntary wheel running of 2 weeks showed reduced anxiety-like behavior (Salam et al., 2009). The discrepancy in our findings for $\mathrm{PE}$ and $\mathrm{PE}+\mathrm{EE}$ effects at a young age could be attributed to differences in cages, running wheel dimensions, or handling time during the experiment and may require further validation. However, there also is evidence to suggest that physical exercise is anxiogenic in young male C57BL/6 mice (Fuss et al., 2010) and has no effects on anxiety-like behavior in young male SpragueDawley rats (Kim et al., 2004). In the former study, however, mice were single-housed, and social isolation is an established etiology for the onset of psychological stress and subsequent anxiety-like behavior in rodents (Hart et al., 2010).

\section{Short-term PE induces depressive-like behavior at an early age}

EE mice showed the least depressive-like behavior among all groups at 4, 9, and 14 months of age, although results were not significant when compared to controls. EE has been shown to attenuate depressive-like behavior associated with prenatal chronic stress (Yang et al., 2006) but not with early life stress (Cui et al., 2006). We house mice in controlled environmental conditions where chances of stress were minimal. Hence, it is possible that the non-significant results for $\mathrm{EE}$ and $\mathrm{PE}+\mathrm{EE}$ in FST could be due to the short duration of the treatment, and hence longer treatment with $\mathrm{EE}$ could be more effective in the treatment of depressive-like behavior. Like EE, PE+EE mice were not significantly different to control mice for depressivelike behavior at all ages. PE, however, acted as an inducer of depressive-like behavior at 4 months of age, as evidenced by significantly higher immobility time of 4-month PE mice compared with both 4-month-old controls and EE mice in the FST. However, research has shown that moderate PE alleviates depressive-like behavior in rodents (Duman et al., 2008; Patki et al., 2014; Carek et al., 2011). Indeed, our finding contradicts another similar research where voluntary wheel running of 3-4 weeks produced an antidepressant-like behavioral response in the FST in 8- to 10-week-old wild-type mice (Duman et al., 2008). No sex differences were observed for depressive-like behavior. The longer immobility time in FST could represent a faster adaptation of young PE mice to an acute stressor, thereby switching from active to passive behavior to conserve energy for better survival (Molendijk \& de Kloet, 2015). However, in the absence of similar adaptation by PE mice at middle and late-middle age, the longer immobility time of young PE mice in FST during our experiments is indicative of depressive-like behavior and not coping strategy, since we find no reason for PE mice losing their capability to adapt to an acute stressor after young age. The discrepancy in our findings for PE in FST from past studies could be due to differences in cages, running wheel dimensions, or handling time during the experiment and may require further validation.

\section{Short-term PE adversely affects spatial learning of female mice at early and late-middle age. Short-term EE improves retention of spatial learning at late-middle age}

The observed impaired spatial learning in 4- and 14-monthold PE mice was primarily driven by 4 - and 14-month female $\mathrm{PE}$, showing significantly higher latency to escape than agematched female controls. At 14 months, PE mice also showed significantly lower spatial learning than EE and PE+EE mice, with contribution from both PE sexes but more significantly from female PE mice. The analysis of entry errors also shows a trend for male and female PE mice low on spatial learning. Overall, this suggests that $\mathrm{PE}$ at a young age and late-middle age may affect spatial learning of female $\mathrm{C} 57 \mathrm{BL} / 6$ mice adversely.

Furthermore, analyzing the escape latency of controls in the probe trial of the Barnes maze revealed that while retention of spatial learning improved from 4 to 9 month, it deteriorated after that. Interestingly, EE reversed the age-related decline in spatial memory at 14 months, but without any significant sex differences. EE mice, however, also showed a significantly higher number of entry errors in locating the escape box at 14 months compared with 4- and 9-month EE mice. This low escape latency with a high number of entry errors could indicate higher exploration activity and enhanced cognition in searching the escape box with visual input. These findings on EE that we report comply with the previously published literature. For example, short-term EE without running wheels has been shown to improve spatial memory of the young male Wistar and Sprague-Dawley rats (Falkenberg et al., 1992; Birch et al., 2013). Similarly, short-term EE with running wheel has been shown to improve spatial memory by promoting hippocampal neurogenesis, dendritic arborization, and spine density in the brain of Wistar rats (Leggio et al., 2005; 
Segovia et al., 2006). There is also evidence suggesting that EE from weaning to 4 months of age in rats accelerate the acquisition of spatial information in naïve male Wistar rats (Van Waas \& Soffié, 1996). Because spatial memory is the function of the dorsal hippocampus (Sampedro-Piquero et al., 2013; Lee \& Kesner, 2004), it seems that there is a substantial improvement in the integrity of dorsal hippocampus after EE.

Unlike EE, PE showed detrimental effects on the spatial learning and retention of spatial memory on a Barnes maze test. However, PE has widely been accepted as a modulator of brain functions and shown to improve spatial memory in young, middle age and old age male rodents (Albeck et al., 2006; Anderson et al., 2000; Radák et al., 2001; Nichol et al., 2009; Singhal et al., 2014; Van Praag et al., 1999; Cassilhas et al., 2012; Uysal et al., 2005). Notably, all of these studies except for two utilized only male animals for research. Among the two, one balanced research for gender (Nichol et al., 2009), and the other used only female animals (Anderson et al., 2000) but both reported improvement in the spatial memory after PE. Lack of research on female mice in past studies may be a reason for the discrepancy that we report for spatial learning and memory after PE in this study. The species and strain of rodents also could have a significant influence on the rate of spatial memory acquisition. Moreover, PE in short-term may have served as a stressor at an early age for female C57BL/6 mice. At late-middle age, the adverse effects of PE were seen on both male and female mice, which could be attributed to the altered physiological response of the body to acute physical strain after middle age. This hypothesis, however, needs validation through future research. Other factors, such as the design of our study, cage dimensions, the presence of one wheel per cage, handling frequency, and mouse-mouse interactions, may have played a role as well.

\section{$\mathrm{PE}, \mathrm{PE}+\mathrm{EE}$ elicit differential gene expression at 9 months, but EE has no effect on gene expression at all ages}

There is evidence to suggest that the change in behavior and memory is a measure of hippocampal integrity (SampedroPiquero et al., 2013; Scoville \& Milner, 1957; Schacter et al., 1996; Engin \& Treit, 2007; Campbell \& MacQueen, 2004). Both PE and EE have a considerable influence on the expression of hippocampal genes associated with immune functions, aminergic pathways, neurotrophin metabolism, HPA axis, transcription factors, and mitochondrial function, and this can manifest into known anti-inflammatory, cellproliferative and neuroprotective effects of the two treatments (Falkenberg et al., 1992; Rasmuson et al., 1998; Olsson et al., 1995; Keyvani et al., 2004; Mlynarik et al., 2004; Hullinger et al., n.d.; Buschler \& Manahan-Vaughan, 2017; Torasdotter et al., 1998; Dahlqvist et al., 1999; Zajac et al., 2010; Tong et al., 2001; Rampon et al., 2000; Kaliman et al., 2011). In this context, we analyzed the differential expression of hippocampal genes of interest in response to short-term PE, EE, and combined PE and EE. We found no significant differential expression after all treatments at 4 and 14 months of age; however, at 9 months, a set of genes expressed differentially after PE and PE+EE treatments, whereas EE showed no effect.

The absence of treatment effects on the expression of hippocampal genes during early and late-middle age was unexpected. However, this could be attributed to genes being more responsive to the external environment during middle age than young and late-middle age. In middle age mice, we observed $11,3,6$, and 7 differentially expressed genes during PE vs. controls, PE+EE vs. controls, PE vs. EE, and PE+EE vs. EE comparisons, respectively. None of the genes differentially expressed during EE vs. $\mathrm{C}$ and $\mathrm{PE}$ vs. $\mathrm{PE}+\mathrm{EE}$ comparisons (see Table 5 for the list of differentially expressed genes between the mice groups at 9 months of age). Surprisingly, the differential expression of hippocampal genes after PE at 9 months did not manifest into significant behavioral changes. Mice were tested on a behavioral battery immediately after 4 weeks of treatments. It is possible that the effects of differentially expressed genes on behavior could have appeared at a later time point. Moreover, PE of longer duration may be required for observable behavioral changes that could be correlated to differentially expressed genes. Also, the genes that differentially expressed after PE at 9 months elicit neuroprotective effects, which could have allowed 9-month old PE mice to adapt to behavior similar to the age-matched control mice. All of these hypotheses need to be tested for validity in future research.

We performed pathway analysis for the differentially expressed genes using GeneMANIA to understand the molecular effects PE might have had on mice. Genes that were differentially expressed during simple comparisons between groups were mapped in GeneMANIA (Figure 13) and molecular processes statistically significant at FDR $<0.01$ were noted (Table 6).

Three of the genes, i.e., Creb1, Smad2, and Illr1 were upregulated in all groups with $\mathrm{PE}$ when compared to groups without PE (Table 6), suggestive of the effects of PE and not EE on these genes. Crebl encodes for the transcription factor CREB (cyclic adenosine monophosphate response elementbinding protein), which is involved in the regulation of genes important for neuronal regulation and survival of proteins such as brain-derived neurotrophic factor. The expression of Crebl has been reported to increase in the hippocampus, temporal cortex, and nucleus accumbens of animal models of major depressive disorder and related disorders after chronic treatment with antidepressant drugs (Zubenko et al., 2003; Young et al., 1998; Blendy, 2006). Smad2 mediates TGF- $\beta$ signals controlling a wide variety of cellular processes, including cell differentiation, proliferation, apoptosis, 

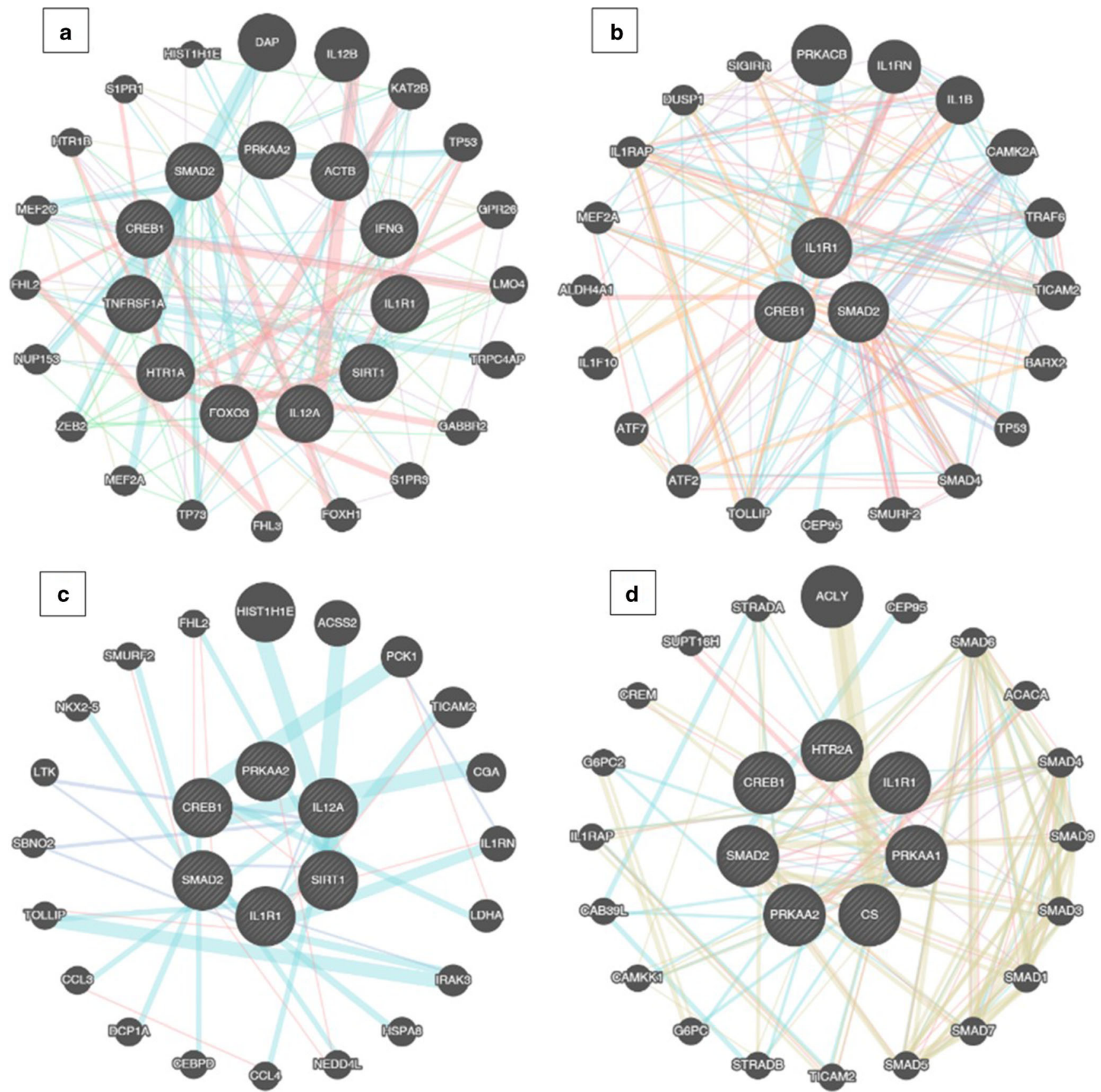

Figure 13 Gene interaction and function prediction network obtained using GeneMANIA for (A) PE vs. C, (B) PE+EE vs. C, (C) PE vs. EE, and (D) $\mathrm{PE}+\mathrm{EE}$ vs. EE. The colors represent significantly modulated molecular pathways.

developmental fate specification, and differentiation of hippocampal granule neurons (Lu et al., 2005; Wang et al., 2011; Bottner et al., 2000). Similarly, IL-1R1 signaling mediates innate and acquired immune responses (Dinarello, 1988), associated with protection or aggravation of the disease states in the CNS, infections, and cancers (Durrant et al., 2014; Wolf et al., 1994). Knocking out these genes have shown to result in apoptotic cell death and affects brain functions and neurobiology adversely (Wang et al., 2011; Castro-Jorge et al., 2017; Becher et al., 2002). The upregulation of these three genes in all groups after $\mathrm{PE}$ at nine months suggests the neuroprotective role of PE, which has also been reported earlier (Campos et al., 2016).

Two of the genes, i.e., Sirt1 and Il12a, were upregulated in PE mice compared to control and EE mice. These genes were not differentially expressed in PE+EE mice. This suggests that the addition of EE to PE reduces the expression of these two genes. Sirt1 gene is a mitochondrial gene that encodes for SIRT1 protein, which influences energy metabolism and is important 
Table 6. Differentially expressed genes and the associated statistically significant key molecular processes as observed during group comparisons

\begin{tabular}{|c|c|c|c|}
\hline $\begin{array}{l}\text { Groups } \\
\text { compared }\end{array}$ & $\begin{array}{l}\text { Differentially } \\
\text { expressed genes }\end{array}$ & $\begin{array}{l}\text { Total links } \\
\text { with the } 20 \\
\text { most related } \\
\text { genes }\end{array}$ & $\begin{array}{l}\text { Statistically } \\
\text { significant key } \\
\text { molecular processes } \\
(\text { FDR }<0.01)\end{array}$ \\
\hline PE vs. C & $\begin{array}{l}9 \text { genes upregulated: } \\
\text { Creb1, Smad2, } \\
\text { Illr1, Sirt1, Ill2a, } \\
\text { Actb, Prkaa2, } \\
\text { Htrla and Foxo3. } \\
2 \text { genes } \\
\text { down-regulated: } \\
\text { Ifng and Tnfrsfla }\end{array}$ & 140 & $\begin{array}{l}\text { Cell-type-specific } \\
\text { apoptotic } \\
\text { processes, } \\
\text { G-protein coupled } \\
\text { receptor activity, } \\
\text { cellular response to } \\
\text { external stimuli anc } \\
\text { regulation of innate } \\
\text { and adaptive im- } \\
\text { mune response. }\end{array}$ \\
\hline $\begin{array}{r}\mathrm{PE}+\mathrm{EE} \\
\text { vs. C }\end{array}$ & $\begin{array}{l}3 \text { genes upregulated: } \\
\text { Creb1, Illr1, } \\
\text { Smad2 }\end{array}$ & 213 & $\begin{array}{l}\text { Immune and } \\
\text { transcription } \\
\text { pathways, such as } \\
\text { pattern recognition } \\
\text { receptors signaling, } \\
\text { transcription factor } \\
\text { binding, and } \\
\text { regulation of innate } \\
\text { immune response. }\end{array}$ \\
\hline PE vs. EE & $\begin{array}{l}6 \text { genes upregulated: } \\
\text { Creb1, Smad2, } \\
\text { Sirt1, Prkaa2, } \\
\text { Il12a, Illr1 }\end{array}$ & 39 & $\begin{array}{l}\text { IL-1 mediated } \\
\text { signaling, cell } \\
\text { apoptotic process, } \\
\text { regulation of } \\
\text { transforming } \\
\text { growth factor-beta } \\
\text { (TGF } \beta) \text { receptor } \\
\text { signaling, and cyto- } \\
\text { kine receptor bin- } \\
\text { ing. }\end{array}$ \\
\hline $\begin{array}{l}\text { PE+EE } \\
\text { vs. EE }\end{array}$ & $\begin{array}{l}7 \text { genes upregulated: } \\
\text { Creb1, Smad2, } \\
\text { Illr1, Htr2a, } \\
\text { Prkaal, Prkaa2, } \\
\text { Cs }\end{array}$ & 165 & $\begin{array}{l}\text { SMAD protein } \\
\text { complex assembly } \\
\text { and binding, } \\
\text { regulation of TGF } \beta \\
\text { receptor signaling, } \\
\text { and positive } \\
\text { regulation of cell } \\
\text { morphogenesis and } \\
\text { differentiation. }\end{array}$ \\
\hline EE vs. C & \multicolumn{3}{|c|}{ None of the genes differentially expressed. } \\
\hline $\begin{array}{l}\mathrm{PE}+\mathrm{EE} \\
\text { vs. PE }\end{array}$ & \multicolumn{3}{|c|}{ None of the genes differentially expressed. } \\
\hline
\end{tabular}

for neuronal plasticity, cognitive functions, as well as protection against aging-associated neuronal degeneration and cognitive decline ( $\mathrm{Ng}$ et al., 2015; Paraíso et al., 2013). PE has been shown to enhance Sirt1 activity (Kaliman et al., 2011). Ill2a gene encodes cytokine IL $12 \mathrm{a}$, which act as a growth factor for activated $\mathrm{T}$ and NK cells, enhance the lytic activity of NK cells, and stimulate the production of IFN- $\gamma$ by resting peripheral blood mononuclear cells. Upregulation of these two genes after PE is again suggestive of the neuroprotective role of $\mathrm{PE}$ at nine months of age.

Other genes that were upregulated in response to $\mathrm{PE}$ or PE+ EE when compared to control or EE mice are Foxo3, Cs, Actb, Prkaa1, Prkaa2, Htrla, and Htr2a. Foxo3 activates genes that preserve cellular quiescence, prevents premature differentiation, and controls oxygen metabolism during aging (Salih \& Brunet, 2008). Foxo3 maintains the neural stem cells (NSC) pool by preventing the premature proliferation of progenitors and preserving the relative quiescence of NSC. Indeed Foxo3 $\mathrm{KO}$ mice were found to have fewer NSC in vivo than wildtype counterparts (Renault et al., 2009). Interestingly, a study has shown that Foxo3 deficient mice are significantly less immobile in FST (Polter et al., 2009), suggesting that Foxo3 regulates the behavioral manifestation of depression. A review validated this further by reporting that Forkhead box $\mathrm{O}$ transcription factor influences the development of major depressive disorder by regulating neuronal morphology, synaptogenesis, and adult hippocampal neurogenesis (Wang et al., 2015). We, however, observed no significant change in depressivelike behavior after PE at middle age. This is because none of the groups, including controls, showed the development of depressive-like behavior at middle age during our experiments.

Mitochondrial genes Cs, Actb, Prkaal, and Prkaa2 were also upregulated in the hippocampus of 9-monthold PE and PE+EE mice when compared to control and EE mice. A study has indeed shown that PE stimulates the expression of mitochondrial genes in the hippocampus (Tong et al., 2001), thus suggesting that there can be a possible link between mitochondrial function and behavioral changes. Moreover, during aging, there is an increase in dysfunctional brain mitochondria, increased oxidation products, and diminished mitochondrial functional activity, resulting in long-term behavioral changes. Moderate exercise has been reported to reverse mitochondrial dysfunction and lower content of oxidation products and improve related neurological performances (Navarro \& Boveris, 2007). Cs encode citrate synthase, an enzyme of the tricarboxylic acid cycle that plays a key role in regulating energy generation of mitochondrial respiration. Actb encodes for protein beta $(\beta)$-actin that forms the structural framework inside developing neurons. PE has been previously reported to upregulate the Cs (Huang et al., 2006) and Actb expression (Cappelli et al., 2008). Prkaa1 and Prkaa 2 genes encode proteins that are the catalytic subunit of the AMP-activated protein kinase (AMPK). AMPK maintains energy homeostasis within cells. Enhanced expression of Prkaal and Prkaa 2 gene has been reported after short-term PE in mice (King-Himmelreich et al., 2016). Together, the upregulation of these mitochondrial genes after PE suggests that short-term PE play a key 
role in cellular energy metabolism and neurogenesis during middle age.

The upregulated Htr $1 a$ and Htr2a genes encode serotonin $1 \mathrm{~A}$ and $1 \mathrm{~B}$ receptors which mediate inhibitory neurotransmission. Inactivation of Htrla and Htr2a genes in mice results in behavior consistent with an increased anxiety and stress response. For example, allelic variation in 5-HT1 A and 5-HT2A receptor expression has been shown to be associated with anxiety- and depression-related personality traits (LópezFigueroa et al., 2004). Studies have shown that PE alters levels of serotonin in the brain of rodents (Brown et al., 1979). Upregulation of Htrla and Htr2a genes, therefore, suggests improved serotonin neurotransmission in the hippocampus after short-term PE at middle age.

The downregulated immune genes Ifng and Tnfrsfla encode IFN- $\gamma$ and members of the TNF receptor family of membrane-bound and soluble proteins that interact with the ligand TNF- $\alpha$. Both IFN- $\gamma$ and TNF- $\alpha$ regulate complex injury promoting proinflammatory and apoptotic and protective cell proliferation and survival roles in the CNS depending on dose, disease phase, and cell development stage (Ottum et al., 2015; Álvarez et al., 2011). Moreover, evidence suggests that IFN- $\gamma$ is involved in modulation of CNS plasticity and the activity of related brain monoamine systems, thereby also regulates memory function and anxiety and depressive states (Litteljohn et al., 2014; Campos et al., 2014). Similarly, $\mathrm{TNF}-\alpha$ has been shown to play a role in the pathophysiology of affective-like behavior (Liu et al., 2012; Haji et al., 2012). The downregulation of Ifng and Tnfrsfla again suggests that $\mathrm{PE}$ at nine months is neuroprotective.

Given the effects of PE on gene expression, as mentioned above, the observed changes in gene expression appear primarily due to the effects of PE and not EE during PE+EE vs. C comparison. It is, however, interesting to find other genes, for example, Prkaa2, Ifng, and Htrla that were differentially expressed after PE lost significance after PE+EE. Also, finding the same genes being upregulated in 9-month PE mice when compared to age-matched controls and EE mice suggests that the EE might have no or minimal effects on the hippocampal gene expression.

\section{A short note on the effects of short-term EE on the hippocampal gene expression}

EE did not alter the expression of any GOI. This contrasts with previously published literature. For example, a study reported that EE upregulates the Htr $5 B$ gene expression and reverses the depression-like state caused by early life seizure experiences (Koh et al., 2007). Likewise, EE in the absence of exercise showed anxiolytic effects in 5-HT1AR KO mice (Rogers et al., 2016). EE has also been shown to modulate the expression of 5-HT receptors in the hippocampus of R6/1 transgenic mice enriched for four weeks, from 8 to 12 weeks of age (Pang et al., 2008). However, the authors also noted gender effects, and the Htr $2 a$ gene differentially expressed only in females. Hence, the observed change in the behavior despite no GOI being expressed differentially after EE could be attributed to gender effects that we could not measure due to low sample size for gene expression analysis. While our behavioral results suggest that EE elicits age-dependent effects on anxiety-like behavior and could be anti-depressive in long-term, longer exposure of EE may be required to elicit significant changes in hippocampal gene expression. We also propose that study confounders such as the age of mice, and differences in the delivery of enrichment such as box dimensions, number/type of toys and how frequently they were changed may have a role to play for the reported change in behavior. Since aging is a known factor for the differential expression of genes in the hippocampus, it is possible that the effects of short-term EE on hippocampal gene expression could be more significant in mice older than late-middle age. Also, we analyzed 43 genes only, which leaves scope for future studies to investigate if other genes are responsible for the change in behavior after EE that we have reported in this study.

Past studies that have reported gene modulation effects of EE also used running wheels to enrich the environment of rodents (Zajac et al., 2010; Braun et al., 2011). Moreover, the absence of EE effects on hippocampal gene expression could be due to factors such as differences in the delivery of enrichment such as box dimensions, number/type of toys (i.e., quantity, quality and complexity of EE) and how frequently they were changed (i.e., the novelty of EE). A study indeed reported that $\mathrm{EE}$, in the absence of running wheels, has limited transcriptomic effects genome-wide (Hart et al., 2010). More research with long-term EE using a wide variety of objects may be required to understand the effects of $E E$ on hippocampal gene expression fully. Also, if the inclusion of running wheels affects gene expression results in EE studies needs to be investigated further, especially when the presence of running wheel alone has been shown to modulate hippocampal gene expression in C57BL/6 mice (Petit-Demouliere et al., 2005; Porsolt et al., 1977).

\section{Limitations of the study}

Several study confounders such as the age of mice, controlled environmental conditions, design of our study, cage dimensions, handling frequency, mouse-mouse interactions, number of wheels per cage, differences in the delivery of enrichment such as box dimensions, number/type of toys and how frequently they were changed may account for findings in our study. Indeed, the paradigms of PE and EE varied greatly across studies in the past. For example, while some researchers provided continuous PE and EE (Segovia et al., 
2006; Marashi et al., 2004), others provided these treatments intermittently to the rodents (Huang et al., 2017; Samorajski et al., 1987). Cage dimensions also varied from small one layered cages (Nakamura et al., 1999) to large multilayered cages (Marashi et al., 2004), and some studies used one (Berardi et al., 2007) and others two wheels per cage (Segovia et al., 2006). Few researchers handled rodents every day (Albeck et al., 2006) while others handled rodents once a week (Leggio et al., 2005). The presence of a dominant/ aggressive mouse can also affect the behavior of the subordinate mouse/mice in a cage (Singhal et al., 2014). Likewise, the presence or absence of running wheels and enrichment objects during home cage test can also affect the results on locomotion. Future studies investigating the longer duration of PE in older transgenic rodent strains relevant to specific disease models and EE with a wide variety of objects in the presence and absence of running wheels may be required to validate our findings. Also, the sex differences analysis for gene expression results could not be performed during our study due to the relatively smaller sample size of gene expression data. Hence, this remains to be a subject for future research.

\section{Conclusions}

Our research work is one of the few to investigate differential effects of PE, EE, and their combination on behavior, memory, and hippocampal gene expression over the lifespan. We observed that short-term EE alleviated age-related cognitive decline and anxiety-like behavior, but without altering hippocampal gene expression. Conversely, PE was found to be detrimental at a young age for both cognitive- and affective-like behaviors and showed no effects at middle and late middle age despite altering hippocampal gene expression. Hence, EE seems to provide a better opportunity to reduce anxiety and depression symptoms in the short-term, and PE might not benefit brain functions as much as short-term EE. Perhaps, $\mathrm{PE}$ of longer duration may be required to elicit observable changes in behavior and memory. We also found it unusual that changes in the expression of genes after PE were not manifested in observable behavioral alterations. We suggest further research with a longer duration of EE and PE and their combination to validate our findings. The gene expression results are in general agreement with studies suggesting that $\mathrm{PE}$ is a major neurogenic and neurotrophic stimulus (Bechara $\&$ Kelly, 2013), and modulator of gene expression (Rampon et al., 2000). This, in turn, also suggests that $E E$ in the absence of exercise improves behavior and enhances memory probably via mechanisms that are independent of BDNF upregulation and neurogenesis in the dentate gyrus. It has been reported that $\mathrm{PE}$ and $\mathrm{EE}$ enhance hippocampal neurogenesis via dissociable pathways: while EE increases the likelihood of survival of new cells, PE increases the level of proliferation of progenitor cells (Olson et al., 2006). Such a protective effect of EE on new cells may explain the beneficial effects of EE that we have reported in this work.

Open practices statement None of the data or materials for the experiments reported here is available online, and none of the experiments was preregistered.

\section{Compliance with ethical standards}

Conflict of interest statement The presented work is supported by the National Health and Medical Research Council Australia (APP 1043771 to BTB). The funders had no role in study design, data collection and analysis, decision to publish, or preparation of the manuscript.

\section{References}

Ahmadiasl, N., H. Alaei, and O. Hanninen, Effect of exercise on learning, memory and levels of epinephrine in rats hippocampus. Journal of Sports Science and Medicine, 2003. 2(3).

Albeck, D.S., et al., Mild forced treadmill exercise enhances spatial learning in the aged rat. Behavioural Brain Research, 2006. 168(2): p. 345-348.

Alomari, M.A., et al., Forced and voluntary exercises equally improve spatial learning and memory and hippocampal BDNF levels. Behavioural Brain Research, 2013. 247: p. 34-39.

Álvarez, S., et al., TNF- $\alpha$ contributes to caspase- 3 independent apoptosis in neuroblastoma cells: role of NFAT. PLoS One, 2011. 6(1): p. e16100.

Anderson, B.J., et al., Exercise influences spatial learning in the radial arm maze. Physiology \& behavior, 2000. 70(5): p. 425-429.

Baune, B.T., et al., Cognitive dysfunction in mice deficient for TNF- and its receptors. Am J Med Genet B Neuropsychiatr Genet, 2008. 147B(7): p. 1056-1064.

Bechara, R.G. and Á.M. Kelly, Exercise improves object recognition memory and induces BDNF expression and cell proliferation in cognitively enriched rats. Behavioural Brain Research, 2013. 245: p. $96-100$.

Becher, B., B.G. Durell, and R.J. Noelle, Experimental autoimmune encephalitis and inflammation in the absence of interleukin-12. The Journal of clinical investigation, 2002. 110(4): p. 493-497.

Benaroya-Milshtein, N., et al., Environmental enrichment in mice decreases anxiety, attenuates stress responses and enhances natural killer cell activity. European Journal of Neuroscience, 2004. 20(5): p. 1341-1347.

Berardi, N., et al., Environmental enrichment delays the onset of memory deficits and reduces neuropathological hallmarks in a mouse model of Alzheimer-like neurodegeneration. Journal of Alzheimer's disease, 2007. 11(3): p. 359-370.

Binder, E., et al., Regular voluntary exercise reduces anxiety-related behaviour and impulsiveness in mice. Behavioural Brain Research, 2004. 155(2): p. 197-206.

Birch, A.M., N.B. McGarry, and A.M. Kelly, Short-term environmental enrichment, in the absence of exercise, improves memory, and increases NGF concentration, early neuronal survival, and synaptogenesis in the dentate gyrus in a time-dependent manner. Hippocampus, 2013. 23(6): p. 437-450.

Blendy, J.A., The role of CREB in depression and antidepressant treatment. Biological psychiatry, 2006. 59(12): p. 1144-1150.

Bottner, M., K. Krieglstein, and K. Unsicker, The transforming growth factor-betas: structure, signaling, and roles in nervous system development and functions. J Neurochem, 2000. 75(6): p. 2227-40. 
Bowling, S.L., J.K. Rowlett, and M.T. Bardo, The effect of environmental enrichment on amphetamine-stimulated locomotor activity, dopamine synthesis and dopamine release. Neuropharmacology, 1993. 32(9): p. 885-893.

Braun, A.A., et al., Comparison of the elevated plus and elevated zero mazes in treated and untreated male Sprague-Dawley rats: effects of anxiolytic and anxiogenic agents. Pharmacology Biochemistry and Behavior, 2011. 97(3): p. 406-415.

Brenes, J.C., O. Rodríguez, and J. Fornaguera, Differential effect of environment enrichment and social isolation on depressive-like behavior, spontaneous activity and serotonin and norepinephrine concentration in prefrontal cortex and ventral striatum. Pharmacology Biochemistry and Behavior, 2008. 89(1): p. 85-93.

Brown, B.S. and W. Van Huss, Exercise and rat brain catecholamines. Journal of Applied Physiology, 1973. 34(5): p. 664-669.

Brown, B.S., et al., Chronic response of rat brain norepinephrine and serotonin levels to endurance training. Journal of Applied Physiology, 1979. 46(1): p. 19-23.

Buschler, A. and D. Manahan-Vaughan, Metabotropic glutamate receptor, mGlu5, mediates enhancements of hippocampal long-term potentiation after environmental enrichment in young and old mice. Neuropharmacology, 2017. 115: p. 42-50.

Campbell, S. and G. MacQueen, The role of the hippocampus in the pathophysiology of major depression. Journal of Psychiatry \& Neuroscience, 2004

Campos, A.C., et al., Further evidence for the role of interferon-gamma on anxiety-and depressive-like behaviors: involvement of hippocampal neurogenesis and NGF production. Neuroscience letters, 2014. 578: p. 100-105.

Campos, C., et al., Exercise-induced neuroprotective effects on neurodegenerative diseases: the key role of trophic factors. Expert review of neurotherapeutics, 2016. 16(6): p. 723-734.

Cappelli, K., et al., Exercise induced stress in horses: selection of the most stable reference genes for quantitative RT-PCR normalization. BMC molecular biology, 2008. 9(1): p. 49.

Carek, P.J., S.E. Laibstain, and S.M. Carek, Exercise for the treatment of depression and anxiety. The International Journal of Psychiatry in Medicine, 2011. 41(1): p. 15-28.

Cassilhas, R., et al., Spatial memory is improved by aerobic and resistance exercise through divergent molecular mechanisms. Neuroscience, 2012. 202: p. 309-317.

Castro-Jorge, L.A., et al., A protective role for interleukin-1 signaling during mouse adenovirus type 1 -induced encephalitis. Journal of virology, 2017. 91(4): p. e02106-16.

Chen, L., et al., Effects of exercise on neurogenesis in the dentate gyrus and ability of learning and memory after hippocampus lesion in adult rats. Neuroscience bulletin, 2006. 22(1): p. 1-6.

Cohen, J., A power primer. Psychological bulletin, 1992. 112(1): p. 155.

Crews 3rd, E., et al., Weight, food intake, and body composition: effects of exercise and of protein deficiency. American Journal of Physiology-Legacy Content, 1969. 216(2): p. 359-363.

Cui, M., et al., Enriched environment experience overcomes the memory deficits and depressive-like behavior induced by early life stress. Neuroscience letters, 2006. 404(1-2): p. 208-212.

Dahlqvist, P., et al., Environmental enrichment alters nerve growth factorinduced gene A and glucocorticoid receptor messenger RNA expression after middle cerebral artery occlusion in rats. Neuroscience, 1999. 93(2): p. 527-535.

Dinarello, C.A., Biology of interleukin 1. The FASEB Journal, 1988. 2(2): p. 108-115.

Donnelly, J., et al., The effects of 18 months of intermittent vs continuous exercise on aerobic capacity, body weight and composition, and metabolic fitness in previously sedentary, moderately obese females. International journal of obesity, 2000. 24(5): p. 566.

Duffy, S.N., et al., Environmental enrichment modifies the PKAdependence of hippocampal LTP and improves hippocampusdependent memory. Learning \& Memory, 2001. 8(1): p. 26-34.

Duman, C.H., et al., Voluntary exercise produces antidepressant and anxiolytic behavioral effects in mice. Brain research, 2008. 1199: p. 148-158.

Durrant, D.M., B.P. Daniels, and R.S. Klein, IL-1R1 signaling regulates CXCL12-mediated $\mathrm{T}$ cell localization and fate within the central nervous system during West Nile Virus encephalitis. The Journal of immunology, 2014. 193(8): p. 4095-4106.

Engin, E. and D. Treit, The role of hippocampus in anxiety: intracerebral infusion studies. Behavioural pharmacology, 2007. 18(5-6): p. 365-374.

Falkenberg, T., et al., Increased expression of brain-derived neurotrophic factor mRNA in rat hippocampus is associated with improved spatial memory and enriched environment. Neuroscience letters, 1992. 138(1): p. 153-156.

Fang, Z.H., et al., Effect of treadmill exercise on the BDNF-mediated pathway in the hippocampus of stressed rats. Neuroscience Research, 2013. 76(4): p. 187-194.

Ferris, L.T., J.S. Williams, and C.-L. Shen, The effect of acute exercise on serum brain-derived neurotrophic factor levels and cognitive function. Medicine \& Science in Sports \& Exercise, 2007. 39(4): p. 728-734.

Frick, K.M. and S.M. Fernandez, Enrichment enhances spatial memory and increases synaptophysin levels in aged female mice. Neurobiology of aging, 2003. 24(4): p. 615-626.

Frick, K.M., et al., Effects of environmental enrichment on spatial memory and neurochemistry in middle-aged mice. Learning \& Memory, 2003. 10(3): p. 187-198.

Fulk, L., et al., Chronic physical exercise reduces anxiety-like behavior in rats. International journal of sports medicine, 2004. 25(01): p. 78-82.

Fuss, J., et al., Voluntary exercise induces anxiety-like behavior in adult C57BL/6J mice correlating with hippocampal neurogenesis. Hippocampus, 2010. 20(3): p. 364-376.

Gentile, A., Z. Beheshti, and J.M. Held, Enrichment versus exercise effects on motor impairments following cortical removals in rats. Behavioral and neural biology, 1987. 47(3): p. 321-332.

Gobbo, O.L. and S.M. O'Mara, Impact of enriched-environment housing on brain-derived neurotrophic factor and on cognitive performance after a transient global ischemia. Behav Brain Res, 2004. 152(2): p. $231-41$.

Gómez-Pinilla, F., et al., Voluntary exercise induces a BDNF-mediated mechanism that promotes neuroplasticity. Journal of neurophysiology, 2002. 88(5): p. 2187-2195.

Görtz, N., et al., Effects of environmental enrichment on exploration, anxiety, and memory in female TgCRND8 Alzheimer mice. Behavioural brain research, 2008. 191(1): p. 43-48.

Griesbach, G.S., D.A. Hovda, and F. Gomez-Pinilla, Exercise-induced improvement in cognitive performance after traumatic brain injury in rats is dependent on BDNF activation. Brain research, 2009. 1288: p. 105-115.

Haji, N., et al., TNF- $\alpha$-mediated anxiety in a mouse model of multiple sclerosis. Experimental neurology, 2012. 237(2): p. 296-303.

Harati, H., et al., Attention and memory in aged rats: impact of lifelong environmental enrichment. Neurobiology of aging, 2011. 32(4): p. 718-736.

Hart, P.C., et al., (2010). Experimental models of anxiety for drug discovery and brain research, in Mouse Models for Drug Discovery. Springer, 299-321. 
Helmich, I., et al., Neurobiological alterations induced by exercise and their impact on depressive disorders. Clinical practice and epidemiology in mental health: CP \& EMH, 2010. 6: p. 115.

Hoffmann, P., P. Thorén, and D. Ely, Effect of voluntary exercise on openfield behavior and on aggression in the spontaneously hypertensive rat (SHR). Behavioral and neural biology, 1987. 47(3): p. 346-355.

Hothorn, T., F. Bretz, and P. Westfall, Simultaneous inference in general parametric models. Biometrical journal, 2008. 50(3): p. 346-363.

Huang, A.-M., et al., Compulsive exercise acutely upregulates rat hippocampal brain-derived neurotrophic factor. Journal of neural transmission, 2006. 113(7): p. 803-811.

Huang, P., et al., Voluntary wheel running ameliorates depression-like behaviors and brain blood oxygen level-dependent signals in chronic unpredictable mild stress mice. Behavioural Brain Research, 2017. 330: p. 17-24.

Hullinger, R., K. O'Riordan, and C. Burger, Environmental enrichment improves learning and memory and long-term potentiation in young adult rats through a mechanism requiring mGluR5 signaling and sustained activation of p70s6k. Neurobiology of Learning and Memory, 2015. 125(Supplement C): p. 126-134.

Hüttenrauch, M., G. Salinas, and O. Wirths, Effects of long-term environmental enrichment on anxiety, memory, hippocampal plasticity and overall brain gene expression in C57BL6 mice. Frontiers in molecular neuroscience, 2016. 9: p. 62.

Izzotti, A. (2009). Gene-environment interactions in non-cancer degenerative diseases. Elsevier.

Jankowsky, J.L., et al., Environmental enrichment mitigates cognitive deficits in a mouse model of Alzheimer's disease. Journal of Neuroscience, 2005. 25(21): p. 5217-5224.

Kaliman, P., et al., Neurophysiological and epigenetic effects of physical exercise on the aging process. Ageing research reviews, 2011. 10(4): p. 475-486.

Keyvani, K., et al., Gene expression profiling in the intact and injured brain following environmental enrichment. Journal of Neuropathology \& Experimental Neurology, 2004. 63(6): p. 598-609.

Kim, Y.-P., et al., Age-dependence of the effect of treadmill exercise on cell proliferation in the dentate gyrus of rats. Neuroscience letters, 2004. 355(1-2): p. 152-154.

King-Himmelreich, T.S., et al., The impact of endurance exercise on global and AMPK gene-specific DNA methylation. Biochemical and biophysical research communications, 2016. 474(2): p. 284-290.

Kobayashi, S., Y. Ohashi, and S. Ando, Effects of enriched environments with different durations and starting times on learning capacity during aging in rats assessed by a refined procedure of the HebbWilliams maze task. Journal of neuroscience research, 2002. 70(3): p. 340-346.

Koh, S., et al., Depressive behavior and selective downregulation of serotonin receptor expression after early-life seizures: Reversal by environmental enrichment. Epilepsy \& Behavior, 2007. 10(1): p. 26-31.

Laviola, G., et al., Beneficial effects of enriched environment on adolescent rats from stressed pregnancies. European Journal of Neuroscience, 2004. 20(6): p. 1655-1664.

Lee, I. and R.P. Kesner, Encoding versus retrieval of spatial memory: double dissociation between the dentate gyrus and the perforant path inputs into CA3 in the dorsal hippocampus. Hippocampus, 2004. 14(1): p. 66-76

Leggio, M.G., et al., Environmental enrichment promotes improved spatial abilities and enhanced dendritic growth in the rat. Behavioural brain research, 2005. 163(1): p. 78-90.
Levin, B.E. and A.A. Dunn-Meynell, Chronic exercise lowers the defended body weight gain and adiposity in diet-induced obese rats. American Journal of Physiology-Regulatory, Integrative and Comparative Physiology, 2004. 286(4): p. R771-R778.

Lin, E.-J.D., et al., Environmental enrichment exerts sex-specific effects on emotionality in $\mathrm{C} 57 \mathrm{BL} / 6 \mathrm{~J}$ mice. Behavioural brain research, 2011. 216(1): p. 349-357.

Litteljohn, D., E. Nelson, and S. Hayley, IFN- $\gamma$ differentially modulates memory-related processes under basal and chronic stressor conditions. Frontiers in cellular neuroscience, 2014. 8: p. 391.

Liu, Y., R.C.-M. Ho, and A. Mak, Interleukin (IL)-6, tumour necrosis factor alpha (TNF- $\alpha)$ and soluble interleukin-2 receptors (sIL-2R) are elevated in patients with major depressive disorder: a metaanalysis and meta-regression. Journal of affective disorders, 2012. 139(3): p. 230-239.

López-Figueroa, A.L., et al., Serotonin 5-HT1A, 5-HT1B, and 5-HT2A receptor mRNA expression in subjects with major depression, bipolar disorder, and schizophrenia. Biological psychiatry, 2004. 55(3): p. 225-233.

Lu, J., et al., SMAD pathway mediation of BDNF and TGF beta 2 regulation of proliferation and differentiation of hippocampal granule neurons. Development, 2005. 132(14): p. 3231-42.

Ma, C.-L., et al., Physical exercise induces hippocampal neurogenesis and prevents cognitive decline. Behavioural Brain Research, 2017. 317: p. 332-339.

Marashi, V., A. Barnekow, and N. Sachser, Effects of environmental enrichment on males of a docile inbred strain of mice. Physiology \& behavior, 2004. 82(5): p. 765-776.

McAfoose, J. and B.T. Baune, Evidence for a cytokine model of cognitive function. Neuroscience \& Biobehavioral Reviews, 2009. 33(3): p. 355-366.

McLay, R.N., S.M. Freeman, and J.E. Zadina, Chronic corticosterone impairs memory performance in the Barnes maze. Physiology \& behavior, 1998. 63(5): p. 933-937.

Messier, S.P., et al., Exercise and dietary weight loss in overweight and obese older adults with knee osteoarthritis: the Arthritis, Diet, and Activity Promotion Trial. Arthritis \& Rheumatology, 2004. 50(5): p. 1501-1510.

Mlynarik, M., B.B. Johansson, and D. Jezova, Enriched environment influences adrenocortical response to immune challenge and glutamate receptor gene expression in rat hippocampus. Annals of the New York Academy of Sciences, 2004. 1018(1): p. 273-280.

Molendijk, M.L. and E.R. de Kloet, Immobility in the forced swim test is adaptive and does not reflect depression. Psychoneuroendocrinology, 2015. 62: p. 389-391.

Morley-Fletcher, S., et al., Environmental enrichment during adolescence reverses the effects of prenatal stress on play behaviour and HPA axis reactivity in rats. European Journal of Neuroscience, 2003. 18(12): p. 3367-3374.

Nakamura, H., et al., Age-changes of brain synapses and synaptic plasticity in response to an enriched environment. Journal of Neuroscience Research, 1999. 56(3): p. 307-315.

Navarro, A. and A. Boveris, Brain mitochondrial dysfunction in aging: conditions that improve survival, neurological performance and mitochondrial function. Front Biosci, 2007. 12: p. 1154-1163.

Ng, F., L. Wijaya, and B.L. Tang, SIRT1 in the brain - connections with aging-associated disorders and lifespan. Frontiers in cellular neuroscience, 2015. 9: p. 64.

Nichol, K., et al., Exercise improves cognition and hippocampal plasticity in APOE $\varepsilon 4$ mice. Alzheimer's \& dementia: the journal of the Alzheimer's Association, 2009. 5(4): p. 287-294. 
Nithianantharajah, J., et al., Gene-environment interactions modulating cognitive function and molecular correlates of synaptic plasticity in Huntington's disease transgenic mice. Neurobiology of disease, 2008. 29(3): p. 490-504.

Novkovic, T., T. Mittmann, and D. Manahan-Vaughan, BDNF contributes to the facilitation of hippocampal synaptic plasticity and learning enabled by environmental enrichment. Hippocampus, 2015. 25(1): p. 1-15.

O'leary, T.P. and R.E. Brown, The effects of apparatus design and test procedure on learning and memory performance of $\mathrm{C} 57 \mathrm{BL} / 6 \mathrm{~J}$ mice on the Barnes maze. Journal of neuroscience methods, 2012. 203(2): p. 315-324.

Olson, A.K., et al., Environmental enrichment and voluntary exercise massively increase neurogenesis in the adult hippocampus via dissociable pathways. Hippocampus, 2006. 16(3): p. 250-260.

Olsson, T., et al., Transcription factor AP-2 gene expression in adult rat hippocampal regions: effects of environmental manipualtions. Neuroscience letters, 1995. 189(2): p. 113-116.

Ottum, P.A., et al., Opposing roles of interferon-gamma on cells of the central nervous system in autoimmune neuroinflammation. Frontiers in immunology, 2015. 6: p. 539.

Pang, T.Y., et al., Altered serotonin receptor expression is associated with depression-related behavior in the R6/1 transgenic mouse model of Huntington's disease. Human molecular genetics, 2008. 18(4): p. 753-766.

Paraíso, A.F., K.L. Mendes, and S.H.S. Santos, Brain activation of SIRT1: role in neuropathology. Molecular neurobiology, 2013. 48(3): p. 681-689.

Patki, G., et al., Moderate treadmill exercise rescues anxiety and depression-like behavior as well as memory impairment in a rat model of posttraumatic stress disorder. Physiology \& Behavior, 2014. 130: p. 47-53.

Petit-Demouliere, B., F. Chenu, and M. Bourin, Forced swimming test in mice: a review of antidepressant activity. Psychopharmacology, 2005. 177(3): p. 245-255.

Petruzzello, S.J., et al., A meta-analysis on the anxiety-reducing effects of acute and chronic exercise. Sports medicine, 1991. 11(3): p. 143-182.

Pham, T.M., et al., Effects of environmental enrichment on cognitive function and hippocampal NGF in the non-handled rats. Behavioural Brain Research, 1999. 103(1): p. 63-70.

Pietropaolo, S., J. Feldon, and B.K. Yee, Environmental enrichment eliminates the anxiety phenotypes in a triple transgenic mouse model of Alzheimer's disease. Cognitive, Affective, \& Behavioral Neuroscience, 2014. 14(3): p. 996-1008.

Polter, A., et al., Forkhead box, class $\mathrm{O}$ transcription factors in brain: regulation and behavioral manifestation. Biological psychiatry, 2009. 65(2): p. 150-159.

Porsolt, R., A. Bertin, and M. Jalfre, Behavioral despair in mice: a primary screening test for antidepressants. Archives internationales de pharmacodynamie et de thérapie, 1977. 229(2): p. 327-336.

Radák, Z., et al., Regular exercise improves cognitive function and decreases oxidative damage in rat brain. Neurochemistry International, 2001. 38(1): p. 17-23.

Rampon, C., et al., Effects of environmental enrichment on gene expression in the brain. Proceedings of the National Academy of Sciences, 2000. 97(23): p. 12880-12884.

Rasmuson, S., et al., Environmental enrichment selectively increases 5 HT1A receptor mRNA expression and binding in the rat hippocampus. Molecular Brain Research, 1998. 53(1-2): p. 285-290.

Renault, V.M., et al., FoxO3 regulates neural stem cell homeostasis. Cell stem cell, 2009. 5(5): p. 527-539.
Richter, S.H., et al., Environmental enrichment ameliorates depressivelike symptoms in young rats bred for learned helplessness. Behavioural brain research, 2013. 252: p. 287-292.

Rogers, J., et al., Dissociating the therapeutic effects of environmental enrichment and exercise in a mouse model of anxiety with cognitive impairment. Translational psychiatry, 2016. 6(4): p. e794.

Salam, J.N., et al., Voluntary exercise in C57 mice is anxiolytic across several measures of anxiety. Behavioural Brain Research, 2009. 197(1): p. 31-40.

Salih, D.A. and A. Brunet, FoxO transcription factors in the maintenance of cellular homeostasis during aging. Current opinion in cell biology, 2008. 20(2): p. 126-136.

Samorajski, T., et al., Voluntary wheel running exercise and monoamine levels in brain, heart and adrenal glands of aging mice. Experimental gerontology, 1987. 22(6): p. 421-431.

Sampedro-Piquero, P., et al., Effects of environmental enrichment on anxiety responses, spatial memory and cytochrome c oxidase activity in adult rats. Brain research bulletin, 2013. 98: p. 1-9.

Schacter, D.L., et al., The role of hippocampus and frontal cortex in agerelated memory changes: a PET study. Neuroreport, 1996. 7(6): $\mathrm{p}$. $1165-1169$

Scoville, W.B. and B. Milner, Loss of recent memory after bilateral hippocampal lesions. Journal of neurology, neurosurgery, and psychiatry, 1957. 20(1): p. 11.

Segovia, G., et al., Environmental enrichment promotes neurogenesis and changes the extracellular concentrations of glutamate and GABA in the hippocampus of aged rats. Brain research bulletin, 2006. 70(1): p. 8-14.

Shepherd, J.K., et al., Behavioural and pharmacological characterisation of the elevated "zero-maze" as an animal model of anxiety. Psychopharmacology, 1994. 116(1): p. 56-64.

Singhal, G., et al., Cellular and molecular mechanisms of immunomodulation in the brain through environmental enrichment. Frontiers in cellular neuroscience, 2014. 8.

Spires, T.L., et al., Environmental enrichment rescues protein deficits in a mouse model of Huntington's disease, indicating a possible disease mechanism. Journal of Neuroscience, 2004. 24(9): p. 2270-2276.

Tong, L., et al., Effects of exercise on gene-expression profile in the rat hippocampus. Neurobiology of disease, 2001. 8(6): p. 1046-1056.

Torasdotter, M., et al., Environmental enrichment results in higher levels of nerve growth factor mRNA in the rat visual cortex and hippocampus. Behavioural brain research, 1998. 93(1-2): p. 83-90.

Uysal, N., et al., The effects of regular aerobic exercise in adolescent period on hippocampal neuron density, apoptosis and spatial memory. Neuroscience letters, 2005. 383(3): p. 241-245.

Van de Weerd, H., et al., Strain specific behavioural response to environmental enrichment in the mouse. Journal of experimental animal science, 1994. 36: 117.

Van der Borght, K., et al., Exercise improves memory acquisition and retrieval in the Y-maze task: relationship with hippocampal neurogenesis. Behavioral neuroscience, 2007. 121(2): p. 324.

Van der Borght, K., et al., Physical exercise leads to rapid adaptations in hippocampal vasculature: temporal dynamics and relationship to cell proliferation and neurogenesis. Hippocampus, 2009. 19(10): p. 928-936.

Van Praag, H., et al., Running enhances neurogenesis, learning, and longterm potentiation in mice. Proceedings of the National Academy of Sciences, 1999. 96(23): p. 13427-13431.

Van Praag, H., et al., Exercise enhances learning and hippocampal neurogenesis in aged mice. Journal of Neuroscience, 2005. 25(38): p. $8680-8685$. 
Van Waas, M. and M. Soffié, Differential environmental modulations on locomotor activity, exploration and spatial behaviour in young and old rats. Physiology \& behavior, 1996. 59(2): p. 265-271.

Wahlsten, D. (2010). Mouse behavioral testing: how to use mice in behavioral neuroscience: Academic Press.

Wang, L., et al., Smad2 protein disruption in the central nervous system leads to aberrant cerebellar development and early postnatal ataxia in mice. Journal of Biological Chemistry, 2011. 286(21): p. 1876618774.

Wang, H., et al., Forkhead box O transcription factors as possible mediators in the development of major depression. Neuropharmacology, 2015. 99: p. 527-537.

Warde-Farley, D., et al., The GeneMANIA prediction server: biological network integration for gene prioritization and predicting gene function. Nucleic acids research, 2010.38(suppl_2): p. W214-W220.

Wolf, S.F., D. Sieburth, and J. Sypek, Interleukin 12: a key modulator of immune function. Stem Cells, 1994. 12(2): p. 154-168.
Yang, J., et al., Enriched environment treatment counteracts enhanced addictive and depressive-like behavior induced by prenatal chronic stress. Brain research, 2006. 1125(1): p. 132-137.

Young, L.T., et al., Increased temporal cortex CREB concentrations and antidepressant treatment in major depression. The Lancet, 1998. 352(9142): p. 1754-1755.

Zajac, M., et al., Wheel running and environmental enrichment differentially modify exon-specific BDNF expression in the hippocampus of wild-type and pre-motor symptomatic male and female Huntington's disease mice. Hippocampus, 2010. 20(5): p. 621-636.

Zubenko, G., et al., Sequence variations in CREB1 cosegregate with depressive disorders in women. Molecular psychiatry, 2003. 8(6): p. 611.

Publisher's note Springer Nature remains neutral with regard to jurisdictional claims in published maps and institutional affiliations. 